\title{
Cost and Environmental Analyses of Reinforcement Alternatives for
}

\section{a Concrete Bridge}

\section{Thomas Cadenazzi ${ }^{a}$, Giovanni Dotellib, Marco Rossinia ${ }^{a}$, Steven Nolan ${ }^{\mathrm{c}}$ and Antonio Nanni ${ }^{\mathrm{a}}$}

${ }^{a}$ Department of Civil, Architectural and Environmental Engineering, University of Miami, 1251

Memorial Dr., MEB 301, Coral Gables, FL 33146, USA

Cadenazzi, Thomas: $\underline{\text { txc470@miami.edu }}$

Rossini, Marco: $\underline{\text { mxr1465@miami.edu }}$

Nanni, Antonio: $\underline{\text { nanni@miami.edu }}$

${ }^{\mathrm{b}}$ Department of Chemistry, Materials and Chemical Engineering “G.Natta”, Politecnico di Milano,

p.zza L. da Vinci 32, 20133 Milano, Italy

Dotelli, Giovanni: giovanni.dotelli@polimi.it

c State Structures Design Office, Florida Department of Transportation, 605 Suwannee St., Tallahassee, FL 32399-0450, USA

Nolan, Steven: $\underline{\text { Steven.Nolan@dot.state.fl.us }}$

Corresponding Author:

Giovanni Dotelli

Department of Chemistry, Materials and Chemical Engineering “G.Natta”, Politecnico di Milano,

p.zza L. da Vinci 32, 20133 Milano, Italy

e-mail: giovanni.dotelli@polimi.it

ph. :0039 0223993232 


\begin{abstract}
Reinforced Concrete (RC) and Prestressed Concrete (PC) structures using conventional materials in aggressive exposure conditions are susceptible to corrosion. Non-corrosive reinforcement materials such as: Glass Fiber-Reinforced Polymer (GFRP) rebars; Carbon Fiber-Reinforced Polymer (CFRP) strands; Stainless-Steel (SS); and Epoxy-coated steel (ECS) reinforcing bars, are attracting attention as more appropriate options in concrete structures. This paper addresses a Life Cycle Cost (LCC) analysis that verifies the cost performance of four different alternative reinforcement bars for the design of a demonstration FRP-RC/PC bridge in Florida, namely Halls River Bridge (HRB). The four different alternatives to be compared are namely Carbon Steel (CS), SS, FRP, and ECS, and the analysis is performed over 100-years. Additionally, a Life-Cycle Assessment (LCA) is included in the analysis to investigate the environmental credentials of the four design alternatives. Cost sensitivity analyses over specific parameters are included. The parameters analyzed are: reinforcement cost, changes in chloride concentration levels over the bridge service life, and discount rate values. Conclusions and recommendations for standard practices and design of future alternative solutions are then presented.
\end{abstract}

\title{
Keywords
}

Halls River Bridge, FRP-RC/PC bridge, life-cycle cost, epoxy coated steel, stainless-steel, sustainable construction, bridge design, decision-making, LCA. 


\section{Introduction}

The 2017 Infrastructure Report Card by ASCE (ASCE, 2017)) states that about $9.1 \%$ of the bridges in USA were structurally deficient in 2016, with an average age of bridges in USA that is increasing: nation-wide, four bridges out of ten are at least 50 years old, and $15 \%$ are 40 to 49 years old. Accordingly, bridge rehabilitation costs have been recently estimated in the order of $\$ 123$ billion, notwithstanding the recent large investments disposed at all levels of government for repairing bridges. In Florida, only about $15 \%$ of the bridges are at least 50 years old, but about 8.5\% of all bridges were closed or weight limited, as of January 2015. For this reason, maintenance action is necessary to guarantee serviceability and safety with the annual costs estimated at more than $\$ 10$ billion (Shepard, 2005). These increasing maintenance costs represent a significant share of bridge ownership costs.

Structural deficiency of bridges, especially in older structures, is mainly due to environmental attack and load effects experienced during their service life. In particular, the main cause of damage in Reinforced Concrete (RC) bridges is corrosion of the carbon steel reinforcement bars, along with cracking and spalling of the cover concrete. This cracking leads to a loss of mechanical performance of the rebars and the surrounding concrete, affecting ultimately the safety of the structure (Sajedi \& Huang, 2019). Corrosion effects are generally more serious for substructures in coastal regions due to the ingress of chlorides ions from seawater, or superstructures in cold regions where large amounts of de-icing salts are used, although all parts of the bridge can be affected to varying degrees in either environment. For this reason, RC bridges need regular monitoring, maintenance, repair, and rehabilitation. To this end, life-cycle engineering provides a valuable tool to plan the bridge construction, operation, and maintenance, considering three main pillars: structural safety; costs; and environmental impacts (Xie, Wu, \& 
Wang, 2018). Moreover, it is possible to adopt cost-effective corrosion management strategies adopting a life cycle perspective (Kere \& Huang, 2019). However, few studies have focused on Life Cycle Costing (LCC) of corrosion resistant civil infrastructure applications. Sajedi and Huang (2005) enumerate some of the most relevant studies, and identified a lack of LCC and LCA studies

on the use of Fiber-Reinforced Polymer (FRP) rebars in RC infrastructures. The present paper aims to fill this gap.

\section{Research significance}

The Halls River Bridge (HRB), as shown in Figure 1 during construction activities, provides a real-world test of RC and Prestressed Concrete (PC) using FRP materials as structural reinforcement. The HRB served as demonstrator for the SEACON-Infravation research project (Rossini et al., 2018) and the Florida Department of Transportation (FDOT) Innovation Challenge (FDOT, 2015). Previous studies (Cadenazzi et. al, 2019a; Cadenazzi et al. 2018) analyzed the cost benefits of FRP materials for a full bridge design, using HRB as case study. However, not all the corrosion-resistant alternatives have been fully investigated. To this end, this paper aims to explore the economic viability of using alternative reinforcing.

A recent Virginia Transportation Research Council report (Sharp et al., 2019) discussed and analyzed the approach to LCC studies, when comparing innovative technologies. However, a lack of a robust and balanced approach toward innovation is missing. There is often an inflationary reaction among some contractors towards innovation due to the perception of increased risk. This reaction eventually leads to incorrect pricing of FRP materials and misleading LCC studies. This paper aims to show the relevance of deterministic and accurate LCC studies for the comparison of innovative solutions with long-term benefits, and the implications of risk aversion by contractors.

\section{Design and materials}


The following four reinforcing materials for RC structures are compared: Carbon Steel (CS); Epoxy-coated steel (ECS); Stainless Steel (SS); and Fiber Reinforced Polymers (FRP). The last three materials are studied and compared with consideration of their corrosion-resistance benefits. Carbon-steel bars are available as Grade 40,60, or 80 and specifications are issued by ASTM A615/A615M (ASTM 2016). The most commonly specified steel bars are Grade 60, with a yield strength of $414 \mathrm{MPa}$, an ultimate strength of $621 \mathrm{MPa}$, and an elastic modulus of $200 \mathrm{GPa}$. This grade of CS reinforcement is assumed as the benchmark case, for the purposes of comparison. Low-relaxation high-strength carbon-steel bars are available as Grade 250 or 270 and specifications are issued by ASTM A416/A416M (ASTM 2018). Grade 270 is used as benchmark in this study with a yield strength of $1676 \mathrm{MPa}$, an ultimate strength of $1860 \mathrm{MPa}$, and an elastic modulus of approximately $195 \mathrm{GPa}$.

RC structures may experience reinforcement corrosion over time that leads to expansion and spalling of the surrounding concrete (Capozucca, 1995). Corrosion of the bars is a deterioration phenomenon which can ultimately lead to failure under external loads. Spalling accelerates the corrosion of adjacent bars and exacerbates long-term maintenance issues. To delay corrosion, a thin barrier layer of epoxy coating can be applied to protect the bar surface; however, especially in Florida, corrosion still remains a significant problem with the use of ECS reinforced concrete, particularly when a longer service life is required (Sagues et al., 1994). The epoxy coating is an effective corrosion inhibitor, but only as long as the coating remains intact. Imperfections and damage to the bar surface during shipping, handling or installation compromise the protective layer and, thus, the bars ability to resist corrosion over time.

ECS bars and strands shall meet all requirements as of ASTM A775/A775M (ASTM, 2017) and have similar mechanical properties as CS bars. ASTM A775/A775M defines ECS as 
reinforcing bars with protective epoxy coating applied by the electrostatic spray method, for providing additional corrosion-resistance. The coating thickness measurements shall be 175 to 300 $\mu \mathrm{m}$ for bars sizes Nos. 10 to 16, and 175 to $400 \mu \mathrm{m}$ for bar sizes Nos. 19 to 57 (ASTM, 2017). ECS strands shall meet the requirements of ASTM A882/A882M (ASTM 2004).

Austenitic SS-316 and duplex 2205 has been selected as the common grades for the SSRC and SS-PC respectively, specifications are provided by ASTM A276/A276M (ASTM 2017) and FDOT (2018a) given the wide range of studies available to date to prove its performance in RC structures (Freire et al., 2010; Abreu et al., 2006; Veleva et al., 2005) and (Moser, 2012) for PC members. The term austenitic refers to the microstructure of the SS, as detailed in (Gedge, 2008). Thus, SS-316 is often considered one of the most suitable choices when selecting an austenitic SS for marine applications. Duplex 2205 is a more recently developed alternative for prestressing strands. Recent studies by Redaelli at al. 2019, show that preliminary results from service life estimations on austenitic SS-304 bars embedded in seawater concrete, assuming a probability of failure of 10\%, guarantee service lives higher than 140 years. Since (Redaelli at al., 2019) refers to a lower SS alloying content (nickel and molybdenum), it is conservative to assume for the purpose of this paper, that the grade SS-316 and 2205 guarantees a service life of 100 years.

FRP represent a proven non-corrosive alternative to CS in new constructions (Spadea et al., 2018). Commercially available solutions include Glass FRP (GFRP) bars for RC and Carbon FRP (CFRP) strands for PC. Deployment of FRP reinforced concrete (FRP-RC) and FRP prestressed concrete (FRP-PC) eliminates the issue of reinforcement corrosion, irrespectively of the concrete mix-design (Bertola et al., 2017). FRP is a brittle composite material, elastic until failure, stronger, but less stiff with respect to CS. The minimum specified values for strength and stiffness of GFRP bars are defined by ASTM D7957 (ASTM, 2017). CFRP strands are not 
regulated at the federal level, but the FDOT Construction Specifications (FDOT, 2018) include minimum specified values for strength and references to applicable acceptance criteria. Design with FRP is regulated by AASHTO LRFD Bridge Design Guide Specifications for GFRPReinforced Concrete (AASHTO 2018b) and AASHTO Guide Specifications for the Design of Concrete Bridge Beams Prestressed with Carbon Fiber-Reinforced Polymer (CFRP) Systems (AASTHO 2018a). The amount of reinforcement required is typically in the order of 1.5 times with respect to steel reinforcement in RC applications whereas for PC applications a ratio of 1 is possible. Design of GFRP-RC is typically governed by service considerations including crackwidth and deflections limits in reason of its relatively low elastic modulus of approximately 45 GPa.

When using non-corrosive reinforcement like SS and FRP it is possible to reduce the clear concrete cover to $50 \mathrm{~mm}$, as opposed to the $76 \mathrm{~mm}$ or $100 \mathrm{~mm}$, typically used in marine substructures from FDOT (FDOT, 2019). Additionally, concrete additives (silica fume, metakaolin, ultrafine fly ash, or for non-submerged applications: corrosion inhibitors) required by FDOT for all CS-RC/PC alternatives in marine environment, do not apply when using SS and FRP (FDOT, 2018a \& 2019).

\section{Bridge Structure}

The HRB is a short-spanned vehicular bridge located in Homosassa, Florida. The bridge is part of a replacement project for an existing structure that reached functional deficiency and aged beyond its service life. Details about the structure of the bridge are discussed by Rossini et al. (2018) and Cadenazzi et al. (2019b) and summarized herein. The structure has five spans for a total length of $56.7 \mathrm{~m}$ and a width of $17.6 \mathrm{~m}$. The water way is tidally affected by seawater contamination, particularly during storms. 
The structure as-built includes 36 CFRP-PC bearing piles, 235 CFRP-PC/GFRP-RC sheet

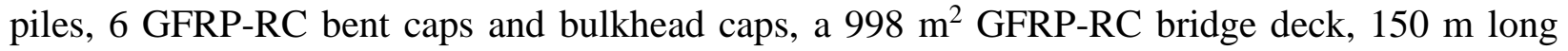
GFRP-RC traffic railings, two $161 \mathrm{~m}^{2}$ GFRP-RC approach slabs and a $20 \mathrm{~m}$ long GFRP-RC gravity wall. The original design implemented Hillman Composite Beams (HCB), consisting of a composite GFRP shell encasing a steel-reinforced concrete shallow tied-arch and lightweight filling foam. An alternative GFRP-RC solution that provides equivalent strength and performance is considered in this study. In addition to innovative reinforcement solutions, the FRP-RC/PC design features the deployment of sustainable concrete mixes in the elements of the substructure. Concrete mixed with seawater is used for the bulkhead cap, concrete with Recycled Concrete Aggregates (RCA) and concrete with Recycled Asphalt Pavement (RAP) aggregates is used for the GFRP-RC gravity walls. White cement concrete and another mixture of high-content slag and fly ash are used in the GFRP-RC traffic railings.

\section{Life Cycle Model}

\subsection{LCC - State-of-the-art}

Traditional LCC frameworks are generally developed as deterministic analyses, whereby designers assign to each input parameter (such as the cost and frequency of maintenance activities) a fixed value. In a probabilistic analysis, the input parameters are stochastic variables based on assumed or documented mean and standard deviation values, and distribution function. Typically, probability distribution functions for the variables considered in the analysis are performed through Monte Carlo simulations (Hatami \& Morcous, 2015). The random sampling model generally includes thousands of iterations that ultimately generates a probability distribution of the maintenance costs.

By comparing a deterministic and probabilistic approach, it is possible to better quantify the 
effects given by the distributions of sensitive parameters that are dependent on uncertain variables. Additionally, for durability-enhancing materials in general, life-cycle optimization frameworks have been recently developed (Yang et al. 2019), in order to maximize the life-cycle performance and minimize the maintenance cost.

The model deployed in this LCC analysis may be considered state-of-the-practice, rather than state-of-art innovation. However, it is the scope of this paper to present a traditional deterministic framework that can serve as a comparative tool for cost and environmental credentials among four different bridge design alternatives. The parameters of uncertainty are taken into account in the deterministic framework through sensitivity analyses.

\subsection{Service life and model boundaries}

The main regulations for life cycle analysis are EN 15804 (EN, CEN, 2013), and ASTM E917/E2453 (ASTM, 2013). The model presented in this paper adopts the same nomenclature and procedures presented in the above standards. As widely discussed by Cadenazzi et al. (2019a), the concept of service life is distinct from the concept of design life. There is a number of studies that identify the 75-year period as service life of bridge projects that use CS as reinforcement (Cadenazzi et al., 2019a), whereas with the adoption of innovative enduring materials, the industry aim to assure an extended service life. The life cycle of the FRP-RC/PC and SS-RC/PC solutions comprise the following:

- Material fabrication (or product stage)

- Construction stage

- Use stage

- End of Life (EoL)

The life cycle of the CS-RC/PC and ECS-RC/PC alternatives is composed by: 
- Material fabrication (or product stage)

- Construction stage

- Use stage

- End of Life (EoL)

- Reconstruction (which includes new material fabrication and new construction stage)

- Use stage for the 25 years of second life.

The latter includes the fact that only 25 years of the second life are included in the analysis, in order to have the CS-RC/PC and ECS-RC/PC alternatives reach 100-years for a consistent comparison of the four different design alternatives. Additionally, the reconstruction activities (and associated costs and environmental burdens) are accounted for by including one third of the initial construction, assuming that the bridge uses the same design criteria, service life expectation, and construction methods of the original bridge.

\subsection{Maintenance model}

Life-365 software (Silica Fume Association, 2017) was used to estimate the maintenance schedule for the design alternatives. A chloride concentration value of $14 \mathrm{~kg} / \mathrm{m}^{3}$ was assumed, and the predicted service life of each alternative was the sum of the corrosion initiation and corrosion propagation periods, after which it was assumed the structure encounters a certain level of damage requiring repair (Ehlen et al. 2009). With regards to the CS-RC/PC and the FRP-RC/PC design solutions, the model considers the same assumptions used in Cadenazzi et al., 2019a. This includes the installation and maintenance of cathodic protections (CP) for bearing piles, and either crack repair, CS-reinforcement rehabilitation, or precast element replacement for the CS-RC/PC solution (Cadenazzi et al., 2019a).

With regards to the CS-RC/PC design solution, the level of chloride penetration that triggers 
corrosion initiation of CS reinforcement is reached at year 12. This value is the corrosion initiation time and for the specific case study is equal to 12 years, time when the chloride threshold of 1.17 $\mathrm{kg} / \mathrm{m}^{3}$ is reached at a concrete depth of $76.2 \mathrm{~mm}$ (Figure 2a). The chloride concentration threshold for CS rebars and strands is influenced by a number of variables, and the value selected in this study is consistent with the results presented in a number of publications (Bentz E., \& Thomas, M.D.A., 2018; Lindquist et al., 2006; Tanaka et al., 2006; Jin et al., 2010; JSCE, 2007). The level of damage that requires the structure repair is found by summing the corrosion initiation and the corrosion propagation periods (Bentz E., \& Thomas, M.D.A., 2018). The corrosion propagation time is equal to 6 years, according to the software Life-365 (Bentz E., \& Thomas, M.D.A., 2018). By applying preventive maintenance on concrete at year 12 (corrosion initiation period) the model assumes that the corrosion propagation period is interrupted.

The preventive maintenance is effectively conducted on the bridge "hot" areas prone to corrosion (Cadenazzi et al., 2019a) so that the corrosion initiation period could restart. However, at year 31, the model assumes that the corrosion propagation period, even though partially interrupted, reached in specific areas its limit and the level of damage that requires the structure essential repair is reached. Figure $2 b$ shows the accumulation of chlorides at the rebar surface (embedded in concrete at a depth of $76.22 \mathrm{~mm}$ ) over time. Figure 2a and Figure 2b refer to both the CS-RC/PC and ECS-RC/PC deterioration model, based on Fick's second law of diffusion. This model assumes that the initial concentration remains constant over the service life of the bridge.

With regards to the ECS-RC/PC alternative, Life-365 suggests that its service life should be that of CS-RC/PC translated by a number of years that is arbitrarily selected. However, being the same grade of CS, it should undergo the same design criteria as CS with a few minor modifications in development length. For this reason, the ECS-RC/PC is an alternative with the same service life 
(75-years) as that of CS-RC/PC, but with an extended routine maintenance interval. In particular, by verifying the steps of the Software Life-365, the maintenance model was found to be translated by 14 years (Bentz E., \& Thomas, M.D.A., 2018). In fact, whereas the corrosion initiation time of ECS remains the same of CS, but the corrosion propagation period is increased to 20 years (Bentz E., \& Thomas, M.D.A., 2018). For this reason, the cathodic protections (CP) of the ECS-RC/PC design alternative are adjusted accordingly, and the patching activities at year 11, and at year 86 (after reconstruction) have been assumed to be minimal activities, similar to those of the SS- and FRP-RC/PC alternatives. However, from year 21 and year 96 onward, the patching activities undergo the same assumptions of the CS-RC/PC alternative.

Maintenance planning strategies include preventive and essential interventions aimed to extend the useful service life of each bridge design alternative (Biondini \& Frangopol, 2016). Figure 3a and Figure $3 \mathrm{~b}$ represent the maintenance strategies selected to minimize the total expected lifecycle cost. Figure 3a refers to the maintenance strategies selected for the CS-RC/PC and ECSRC/PC design solution, whereas Figure 3b refers to maintenance strategies selected for the SSRC/PC and FRP-RC/PC alternative designs.

The FRP-PC/RC maintenance model includes only minimal patching activities on the concrete that conservatively take place every 10 years. FRP materials and concrete, though immune from electrochemical corrosion, do suffer from slow deterioration due to moisture ingress, acid, alkali or sulfate attack, or increased temperatures (Ceroni et al., 2006). Many accelerated lab results and several field studies indicate an estimated $10 \%$ to $30 \%$ reduction compared to the initial tensile strength (Benmokrane, \& Ali, 2016; Robert et al., 2009). However, the design of FRP structures takes into consideration such potential reduction of strength over time by offsetting the initial design strength through the application of an environmental knock-down factor, following the 
design provisions of AASHTO (2018a) as per equation 1:

$$
f_{f d}=C_{e} f_{f u}^{*}
$$

Where: $f_{f d}$ is the design tensile strength of FRP; $C_{e}$ is the environmental reduction factor; and $f_{f u}^{*}$ is the guaranteed tensile strength of the unconditioned FRP bar. The projected performance over 100 years is meant to be above the minimum design requirement, without the need for reinforcement replacement or additional protection (Figure 3b).

The SS-RC/PC design alternative undergoes the same maintenance criteria as the FRPRC/PC alternative, given the high corrosion-resistance properties of SS-316/2205 materials (García-Alonso et al., 2007; Ping et al., 1996; Flint \& Cox, 1988; and Moser, 2012). The most recent version of the software Life-365 used by the authors, confirms the maintenance-free timeline for SS-RC/PC elements in uncracked concrete. The chloride concentration threshold to initiate corrosion for SS is ten times more than the threshold adopted for CS (Bentz, E., \& Thomas, M. D. A., 2018; Srensen, et al., 1990), whereas the propagation period remains the same. Refinement of the propagation period is ongoing under and FDOT research project (Sagues, A. \& Mullins, G., 2018). The chloride concentration threshold for SS rebars and strands rises to 11.7 $\mathrm{kg} / \mathrm{m}^{3}$, which is exceeds the calculated chloride concentration projected by Fick’s law at 100 years (Figure 4). This means that the maintenance timeline is translated by a number of years that is longer than the SS-RC/PC bridge service life. However, the concrete may still require maintenance over time, as needed for the FRP solution, especially given the assumptions of uncracked concrete. For this reason, the preventive maintenance actions of the SS-RC/PC solution consist of the same timeline and operations required for the FRP-RC/PC alternative. Additionally, the SS-RC/PC solution also allows for the same design criteria as the CS- and ECS-RC/PC counterparts, given the similar mechanical properties of the three materials. 
Although pitting corrosion may be a serious problem in some SS reinforcement, causing localized stress concentrating defects (García-Alonso, et al., 2007; Sedrikis, 1996). SS-316 \& 2205 alloys have extended pitting corrosion resistance in the presence of chlorides. Also, as the threshold tolerated by SS rebars and strands is 10 times higher than those of CS (Bentz, E., \& Thomas, M. D. A., 2018; Srensen, et al., 1990; García-Alonso, et al., 2007), pitting corrosion issues are not triggered for the chloride concentration levels of the specific case study. García-Alonso, et al. (2007) found to be very improbable the pitting corrosion initiation of SS 316 rebars embedded in concrete with chloride additions that were approximately two times the chloride content of the present study. Additionally, the case study of Progreso Pier in Yucatan (Mexico), built between 1937 and 1941 (Arminox, 1999), supports the SS-RC/PC degradation model adopted in this study. Progreso Pier was reinforced with AISI 304 SS rebars (Arminox, 1999), which is a lower grade alloy compared to the that selected for this study.

Figure 5 shows the life cycle stages of the four design alternatives.

\section{LCC Analysis}

\subsection{Material cost}

Product stage refers to the fabrication of the reinforcement bars. The product stage cost data of several design alternatives were taken from reports provided by government agencies, private industries and commercial software. For a comparison of these individual costs, see Table 1.

\subsubsection{Carbon-steel alternative}

CS rebars and strands are generally priced by unit weight. The unit cost of CS rebars is 1.32 USD $/ \mathrm{kg}$, and that of CS strands is considered to be $3.30 \mathrm{USD} / \mathrm{kg}$. The cost of the concrete mix for the CS-RC/PC alternative is estimated by adding to traditional concrete mixes the cost of silica fume (HRP) is required to achieve the intended service life. The addition of silica fume to 
the concrete mix increases the cost of prestressed concrete elements by $19.69 \mathrm{USD} / \mathrm{m}^{3}$ and increases the cost of cast-in-place elements by 52.32 USD $/ \mathrm{m}^{3}$ (FDOT, 2019).

\subsubsection{Epoxy-coated steel alternative}

Similar to CS rebars and strands, ECS reinforcement is priced by unit weight. The unit cost of ECS rebars and strands is assumed to be 33\% more expensive than CS counterparts. Such a price difference is provided by the software Life-365. In fact, the cost of ECS bars in Life-365 is 1.32 USD $/ \mathrm{kg}$, whereas the cost of CS bars is $0.99 \mathrm{USD} / \mathrm{kg}$. Given the fact that these unit costs are dated, the authors applied the calculated difference to the current prices in the U.S. As such, the unit cost of ECS bars is $1.76 \mathrm{USD} / \mathrm{kg}$ (whereas the cost of CS bars is $1.32 \mathrm{USD} / \mathrm{kg}$ ), and that of ECS strands is $4.39 \mathrm{USD} / \mathrm{kg}$ (whereas the cost of CS strands is $3.30 \mathrm{USD} / \mathrm{kg}$ ). With regards to the cost of CS bars and strands, the first author accessed historical steel cost rebars from contractors’ past experience and found an average of $1.32 \mathrm{USD} / \mathrm{kg}$ as average cost of steel rebar. The unit cost shown is in line with current available estimates and FDOT's publicly accessible reports for historical bid prices (FDOT, 2018b). Similarly to the CS-RC/PC alternative, the ECS-RC/PC solution accounts for the inclusion of silica fume in the concrete mix design.

\subsubsection{Stainless-steel alternative}

Austenic stainless-steel (SS) alloy 316 was selected as primary reinforcement and duplex 2205 for the prestressing strand in the SS design alternative, to improve the corrosion resistance the aggressive environment for at least a 100-year service life. The unit cost of SS-316 rebars is assumed to be 8.82 USD/kg, as per (FDOT, 2019). Thus, the ratio between CS rebars and SS rebars can be calculated as approximately 6.68. The cost of SS strands, instead, is translated from the unit cost of CS strands, and then multiplied by the cost ratio found between CS rebars and SS rebars. The use of SS as primary reinforcement in corrosive environments may allow the use of traditional concrete mixes in some jursidictions, and the reduction of concrete cover from $76.2 \mathrm{~mm}$ to 50.8 
$\mathrm{mm}$, for the elements composing the bridge substructure, however for SS prestressed elements in marine environments FDOT still recommends supplemental HRP in the concrete (FDOT, 2018a \& 2019).

\subsubsection{FRP alternative}

GFRP rebars and CFRP strands are priced by unit length. Table 1 shows documented FRP unit cost for the several diameters available. The unit costs of FRP rebars were those from the HRB project. Additionally, similar to the SS-RC/PC alternative, and construction plans, the FRP-RC/PC accounts for a reduced concrete cover of substructure elements and use of conventional concrete mix designs.

\subsection{Construction Stage}

The costs incurred at the construction stage account for material transport activities from manufacturing plant to site and labor and equipment required for material installation, such as concrete formwork, concrete casting tools, and reinforcement cage installation. All data regarding construction activities were collected during the construction phase of the bridge project. Construction costs of ECS-RC/PC and SS-RC/PC alternatives are shown in Table 2 and Table 3, respectively.

Even though some researchers (Younis et al., 2018; Brown, 2015) account for expected efficiency savings during construction phase of FRP-reinforced projects in LCC analyses, this paper does not take into consideration such potential reduced costs. The costs related to the installation of additional reinforcement equal the savings given by faster and less expensive installation methods for FRP-RC/PC elements, as demonstrated by Cadenazzi et al., 2019b. The design of the FRP-RC/PC solution accounts for more reinforcement because of several FRP properties and current design limitations, such as their lower elastic modulus which negatively affect the deflections and crack widths, and limited creep-rupture resistance properties that affect 
the long-term performance of the structure. Thus, this paper accounts for the inflated FRP-to-CS reinforcement ratios presented and discussed by (Cadenazzi et al., 2019a).

\subsection{Use Stage}

The use stage accounts for the maintenance and repair activities of precast/prestressed bearing piles and sheet piles that compose the bridge substructure. Table 4 shows all maintenance operations of the four alternatives and, for convenience, is split into two sections. The first portion of the table shows the absolute costs related to each alternative maintenance operation. The second portion of the table shows the costs breakdown by years of the maintenance and repair activities for each design alternative, conservatively assuming a discount rate of $1 \%$. Costs data were obtained from FDOT historical cost database (FDOT, 2018b).

\subsection{End of Life Stage}

The EoL stage refers to demolition, disposal, and eventual reconstruction activities of the design alternatives. CS, as well as ECS and SS, are a fully recyclable metals whose scrap can be reconverted to comparable or even higher grades (Broadbent, 2016). This paper accounts for $90 \%$ of the original steel quantities to be resold at the end of its life, by considering a price for recycling prepared scrap CS of $0.18 \mathrm{USD} / \mathrm{kg}$ (Cadenazzi et al., 2019a). The total steel quantity recycled is an estimated 30,088 USD at EoL.

FRP has complex characteristics that make it a challenging material to be recycled, with research still in progress to address this issue (Dehghan et al., 2017; Correia et al., 2011; Yazdanbakhsh and Bank, 2014). Additionally, no actual pricing for re-use of FRP materials is available to the authors' knowledge. For these reasons, landfill disposal was considered for FRP reinforcement at EoL.

Concrete is estimated to be recycled into roadbeds or RCA (recycled concrete aggregate) (Cadenazzi et al., 2019a). Similarly to CS, 90\% of the concrete is assumed to be resold, and the 
estimated return is 167,633 USD at EoL.

\subsection{Net Present Value}

As detailed in ISO 15686-5 (ISO 15686-5, 2008), the net present value (NPV) is the sum of all partial costs incurred over the entire life cycle, considering the time value of money, which is calculated in Equation (1).

$$
N P V=\sum_{n=0}^{N} \frac{C_{n}}{(1+r)^{n}}
$$

In (1) $C_{n}$ is the sum of all cost incurred at a year $n ; N$ is the number of periods in the study period; and $\mathrm{r}$ is the discount rate. The discount rate is a sensitive factor in the calculation of NPV, as it reflects the value of money over time (Haghani and Yang, 2016). In this paper, a discount rate of $1 \%$ was assumed. The selected value is conservatively higher (67\%) with respect to the value recommended by the White House Office of Management and Budget (OMB) in circular A-94 (revised November 2017) (White House Office of Management and Budget, 2017) for long-term federal investments ( $\geq 30$ years). Typical commercial discount rate values for long-term investments range between 1\% and 8\% (Mistry et al., 2016). The present work considers a public works discount rate of 1\%, based on a previous study Cadenazzi et al. (2019a). However, given the influence of the discount rate value over the LCC analysis, a sensitivity analysis is performed for a broad range of values $(0 \%-10 \%)$.

\section{LCA Analysis}

For a deeper investigation of the environmental loading and comparison of several durabilityenhancing materials, a Life Cycle Assessment study (LCA) is also included. Scope definition and LCA methods are based on Cadenazzi et al., 2019a. This includes the criteria provided by ISO 14040 (ISO 14040:2006) and ISO 14044 (ISO 14044:2006). The life cycle impact assessment 
(LCIA) is based on the methodology "Tool for the Reduction and Assessment of Chemical and other environmental Impacts” (TRACI, version 2.1, 2012), recommended by ISO 21930:2017.

The database Ecoinvent (version 3.4, 2017) was also used as source of secondary data. The impact categories selected for the purposes of comparison are: Ozone Depletion Potential (ODP), Global Warming Potential (GWP 100), Photochemical Oxidant Creation Potential (POCP), Acidification Potential (AP), and Eutrophication Potential (EP). The analysis is performed from cradle-to-gate (raw materials, transportation, and construction) and from cradle-to-grave (raw materials, transportation, construction, maintenance, and EOL). The software used for the analysis is SIMAPRO (version 8.5.2.0, 2018). Cadenazzi et al., 2019a investigated the environmental credentials of the FRP-RC/PC and CS-RC/PC solutions. This paper extends the analysis to the ECS-RC/PC and SS-RC/PC alternatives. Additionally, the accumulation of the major environmental impacts over the life cycle of the bridge for each alternative is included in the analysis.

\section{Results and Discussion}

The economic and environmental results of the design alternatives are reported independently. Even though recent efforts are aiming to link the LCC and LCA analyses (Moschetti \& Brattebø, 2017; Ristimäki et al, 2013), currently there is no available regulation or agreed upon methodology that combines both. In the existing studies, the combined analyses have been predominantly performed for the assessment of residential building projects. Future investigations are required to explore a methodological approach that combines LCC and LCA for infrastructural applications. The findings may be helpful in the decision-making process towards a meaningful combination of environmental and economic assessments in infrastructural projects for selecting the most beneficial scenario. 


\subsection{LCC}

Figure 6 shows the cumulative LCC analysis of the four design alternatives with a spectrum of corrosion-resistant reinforcing materials. As shown in Figure 6 and detailed in Table 5, the NPV of the ECS-RC/PC is only $0.75 \%$ lower than that the CS-RC/PC alternative, indicating a limited high cost performance of the former in the long term. Likewise, the SS-RC/PC solution has an NPV which is $10.37 \%$ lower than the NPV of the CS-RC/PC alternative, and $9.60 \%$ lower than the NPV of the ECS-RC/PC alternative. The FRP-RC/PC solution revealed to be the most costeffective solution, with an NPV that is approximately $20 \%$ lower than that of the CS-RC/PC counterpart. Additionally, the FRP-RC/PC solution has approximately an NPV which is $19.30 \%$ and $14.92 \%$ lower than the ECS-RC/PC and the SS-RC/PC solutions, respectively. Despite the lower preliminary costs associated with the CS-RC/PC and the ECS-RC/PC, the two most effective corrosion-resistant designs (FRP-RC/PC and SS-RC/PC alternatives) revealed long-term cost savings as they resulted in longer service lives and lower repair costs throughout the analysis period.

FRP-RC/PC revealed to be the optimal solution, with a lower initial investment compared to the SS-RC/PC solution, and a lower NPV in the long term. However, as the market for SS rebars enlarges, and the material becomes more economical and competitive, the SS-RC/PC solution could be an optimal alternative, allowing for the traditional design of RC members, along with all the positive and peculiar aspects of behavior of CS-RC/PC members (in terms of mechanical properties as well as intrinsic recyclability properties).

Additionally, a cost breakdown analysis, based on the selected discount rate (1\%), is presented in Figure 7. The construction costs are subdivided into two categories. The construction cost that are dependent of the selection of reinforcement, and the construction costs that are independent of the reinforcing material selected. Despite the lower material-dependent construction costs of the 
CS-RC/PC and the ECS-RC/PC design alternatives, the material-independent construction costs are the same for the four alternatives. The latter includes all the costs that are independent from the selection of the reinforcement material, such as: operating expenses; mobilization of equipment and materials; maintenance of traffic devices; temporary barrier walls; quality assurance and quality control; survey activities; bridge temporary works; rip-rap installation; concrete slope pavements; grooving and grinding activities; erosion control; utilities; drainage systems; excavations; embankments; asphalt and concrete flatworks; guardrails installation; signage; and pavement marking, all necessary to complete the bridge.

Finally, Figure 7 shows the cost impacts of maintenance, demolition and reconstruction activities of the four design alternatives. The demolition cost of the SS-RC/PC is slightly lower than the FRP-RC/PC. This is because the recycling of SS at EoL is considered. For the CS-RC/PC and ECS-RC/PC alternatives the demolition and reconstruction activities are combined, as they take place contemporary at year 75 (bridge replacement).

\subsection{LCA}

Table 6 and Table 7 show the environmental impacts of each design alternative. Table 6 lists the environmental emissions of each design alternative from cradle-to-gate, whereas Table 7 refers to the impacts from cradle-to-grave.

To better visualize the LCA impacts over the service life of the design alternatives, Figure 8 and Figure 9 show the results breakdown by years for two of the most relevant categories and most commonly known, i.e. global warming and photochemical oxidant creation (commonly referred as smog).

As shown in Table 7, the FRP-RC/PC alternative outperforms in four out of five categories the CS-RC/PC and ECS-RC/PC solutions. The only category where the FRP-RC/PC solution is not environmentally competitive is the ozone depletion. However, the impacts are minimal in terms 
of order of magnitude (the absolute values are in order of decimals), and the reason is strictly correlated to the carbon-fibers outdated database used as data input in the software (Cadenazzi et al., 2019a). Similarly, the SS-RC/PC alternative is well performing in three out of five categories, making it the first competitor to the FRP-RC/PC solution. However, given the great amount of thermal energy needed for the production of stainless-steel rebars and strands, this design alternative has a large contribution in terms of global warming. There is a net difference of 35,508 $\mathrm{kg} \mathrm{CO}_{2}$ eq. between the FRP-RC/PC solution and the SS-RC/PC alternative, making the former option a very appealing choice. Ultimately, the ECS-RC/PC is the least environmental-friendly solution. There is not a single category for which the ECS-RC/PC is an ideal alternative. This is due to the large contribution of the epoxy coated layer needed for the protection of rebars and strands, estimated to be approximately 2,910 liters for the protection of all the bridge reinforcement.

Demolition and landfill activities at EoL contribute to a significant proportion of both carbon and ozone emissions, as shown in Figure 8 and Figure 9. On the other hand, each maintenance activity has very little impact on the overall life-cycle trend, in particular for the FRP-RC/PC and SS-RC/PC solutions. This is due to the fact that maintenance plan of FRP and SS materials do not require major operations (such as cathodic protections or reinforcement replacement), and, thus, do not require traffic disruptions or traffic diversions. Lastly, the reconstruction activities (accounted for one third of the initial construction emissions), contribute to a major portion of the life-cycle emissions of the CS-RC/PC and ECS-RC/PC solutions.

\section{Sensitivity Analysis and uncertainty of critical aspects}

Since the NPV is affected by the value of the discount rate, a sensitivity analysis is performed and shown in Figure 10, to determine the best solution for each discount rate. The change in the 
discount rate has minimal effect on the overall NPV of the FRP-RC/PC or SS-RC/PC alternatives, given the low-maintenance costs over time of these two corrosion-resistant solutions. Conversely, the change in discount rate highly affects the CS-RC/PC and the ECS-RC/PC alternatives, which experience relevant maintenance operations over time, and a reconstruction cost. The breakeven point for the FRP-RC/PC cost-effective solution occurs at a discount rate of $4.0 \%$ when compared to the CS-RC/PC alternative, and at a discount rate of $4.2 \%$ when compared to the ECS-RC/PC alternative. As expected, the FRP-RC/PC solution never intersect the SS-RC/PC curve, to indicate that the solutions are only affected by the initial investment of construction. The breakeven point for the SS-RC/PC cost-effective solution occurs at a discount rate of $2.0 \%$ when compared to both the CS-RC/PC and the ECS-RC/PC alternatives. Similarly, the breakeven point of the CS-RC/PC alternative occurs at a discount rate $2.0 \%$ when compared to the ECS-RC/PC design. In a scenario where the discount rate is higher than $4.0 \%$, the FRP-RC/PC solution is no more cost-effective. Similarly, in a scenario where the discount rate is higher than $2.0 \%$, the SS-RC/PC solution is no more cost-effective.

Furthermore, in selecting the most effective solution, some additional aspects of uncertainty need to be introduced. For example, the probability that one reinforcement alternative is less costly than another (Eamon et al., 2012), or moreover the changes of chloride concentration over time (Xie et al., 2018). With regards to the reinforcement cost variance over the life-cycle of the bridge, the authors selected a price variance range that goes from minus (-)18\% to plus $(+) 18 \%$. This is based on the price fluctuation of steel during the past 10 years (Figure 11), for which the authors calculated a coefficient of variation of $18 \%$ (Figure 11). For this reason, the sensitivity analysis accounts for a price variation of reinforcement that goes from plus or minus $( \pm) 18 \%$, for each design alternative. As shown in Table 8, and illustrated in Figure 12, the identified range allows 
for overlaps at the boundary zones. These boundary zones represent specific scenarios that may influence the final design selection. In the extreme scenario, where the FRP price increases $18 \%$, and the SS price decreases $18 \%$, the SS-RC/PC is the most viable solution. Similarly, if the price of SS rebars increases $18 \%$ and the price of CS and ECS rebars decreases 18\%, the SS-RC/PC is no more a cost-effective solution. However, any FRP price increment over a CS price decrement, or ECS price decrement would not be sufficient for justifying selection of traditional CS reinforcement rather than SS or FRP corrosion-resistant reinforcement.

Finally, climate change likely contributes to changes in LCC scenarios, too. Xie et al., 2018, with the use of a reliability-based method, evaluated the influence of climate change on the durability of offshore RC bridges considering the acceleration of chloride ion penetration caused by temperature rise (Xie et al., 2018). Xie et al., 2018 estimated a 6\% to 15\% increase in chloride concentration over 100 years. Adopting the same methodology and the same variation range found by Xie et al., 2018, a chloride concentration variance over time (at depth $76 \mathrm{~mm}$ ) is presented in Figure 13 for the CS-RC/PC alternative and the ECS-RC/PC.

For the CS-RC/PC and the ECS-RC/PC alternatives, the 6\% and 15\% increments of chloride concentration over time translates into approximately 6 and 12 months shortening of anticipated maintenance intervals for every maintenance action. In fact, the chloride concentration threshold $\left(1.17 \mathrm{~kg} / \mathrm{m}^{3}\right)$ is reached at year 11.5 and year 11 for increments of $6 \%$ and $15 \%$, respectively. In this way, the climate change only affects the timing of intervention. The type of maintenance (amount of material, amount of reinforcement and type of interventions) remains the same. The maintenance activities are only anticipated in years. This fact would have an impact on the preventive maintenance schedule only, affecting thus the costs by means of the discount rate.

As expected, the NPV of the CS-RC/PC alternative is more sensitive to a maintenance schedule 
change, rather than the ECS-RC/PC solution. This is because the ECS-RC/PC solution requires essential maintenance interventions later in time, when the discount rate has less impact on the LCC. On the other hand, FRP-RC/PC and SS-RC/PC alternatives are not influenced by increment of salient chloride concentrations for values up to 15\%. In the case of SS-RC/PC, the upper bound of chloride concentration at year 100 for the increment rate of $15 \%$ is still within the acceptable limits for avoiding pitting corrosion. Table 9 and Figure 14 show the LCC results over changes in chloride concentrations.

\section{Conclusions}

A life-cycle cost comparative analysis of a RC/PC bridge was presented in this paper. A case study was used to validate the proposed model and compare three corrosion-resistant alternatives to a traditional CS-RC/PC solution. The following conclusions can be drawn:

- Despite its relatively low material cost, modelling shows that the ECS is not a cost effective corrosion-resistant solution. As the protective coating layer is damaged or exhibits imperfections, the CS surface is at risk of corrosion and the reinforced structure can rapidly loose its functionality. Thus, for long-term applications in aggressive environments, the use of ECS is not recommended.

- The cost of CS rebars and strands is lower with respect to FRP, SS, and ECS rebars and strands. For this reason, the initial construction cost of the CS-RC/PC alternative is 3.93\% lower than the ECS-RC/PC alternative, 8.33\% lower than the FRP-RC/PC alternative, and 18.70\% lower than the SS-RC/PC alternative.

- The FRP-RC/PC and SS-RC/PC alternatives show economic and environmental benefits over the long term. The net savings associated to the two alternatives are respectively 1,570,670 USD and 814,969 USD, respectively for this example. Conversely, the ECS- 
RC/PC alternative shows only 67,085 USD of net savings, which is only $0.85 \%$ of the initial investment.

- The SS-RC/PC alternative outperforms in all the impact categories the CS-RC/PC and ECS-RC/PC alternatives. Additionally, the SS-RC/PC solution is performing slightly better than the FRP-RC/PC solution in three out of five categories. However, a substantial net difference between the SS-RC/PC and the FRP-RC/PC alternative in terms of global warming emissions, makes the latter solution more environmental appealing.

- Results are sensitive to the selection of the discount rate. For this reason, a sensitivity analysis was performed. The FRP-RC/PC alternative shows no economic advantage at discount rates higher than $4 \%$. Similarly, the ECS-RC/PC and SS-RC/PC alternatives are not cost-effective when the discount rate is higher than $2 \%$.

- Results are also slightly sensitive to some parameters of uncertainty, such as the reinforcement costs and climate change scenarios. With regards to changes in reinforcement costs in the range of plus or minus $( \pm) 18 \%$, the FRP-RC/PC solution is always the most cost-effective solution when compared to CS-RC/PC and ECS-RC/PC alternatives. However, the SS-RC/PC may become the viable solution if cost of the SS rebars and strands reduces 18\%, and cost of the FRP rebars and strands increases $18 \%$ from assumed unit rates.

These findings are based on a life-cycle model, durability assumptions, and data that are specific to the case of the Halls River Bridge. Future studies are necessary to determine the cost benefits of other configurations and add more data to the archival literature with regards to the economic and environmental implications of innovative and alternative materials used for reinforced and prestressed concrete structures. 


\section{Acknowledgments}

Infravation program under grant agreement No. 31109806.005-SEACON is acknowledged as it made possible the presence of the first author to the job site. The findings of this paper are based on the authors' ideas and opinions, that not necessarily are those of the sponsor or the Florida Department of Transportation. 


\section{References}

AASHTO. (2018a). AASHTO Guide Specifications for the Design of Concrete Bridge Beams Prestressed with CFRP Systems (1st ed.). Washington, DC: American Association of State Highway and Transportation Officials. AASHTO. (2018b). AASHTO LRFD Bridge Design Guide Specifications for GFRP-Reinforced Concrete (2nd ed.). Washington, DC: American Association of State Highway and Transportation Officials.

Abreu, C. M., Cristóbal, M. J., Losada, R., Nóvoa, X. R., Pena, G., \& Pérez, M. C. (2006). Long-term behaviour of AISI 304L passive layer in chloride containing medium. Electrochimica Acta, 51(8-9), 1881-1890.

ACI Committee 440. (2015). Guide for the Design and Construction of Structural Concrete Reinforced with FiberReinforced Polymers (FRP) Bars. ACI 440.1R-15. Farmington Hills, MI: American Concrete Institute.

Arminox Aps. (1999). International Report, Evaluation of the stainless steel reinforcement of Pier of Progresso, Mexico. March 1999.

ASCE. (2017). 2017 Infrastructure Report Card. Retrieved from: https://perma.cc/D9E2-JYHZ

ASTM A775 / A775M-17. (2017). Standard Specification for Epoxy-Coated Steel Reinforcing Bars, ASTM International, West Conshohocken, PA, 2017.

ASTM. (2004). Standard Specification for Filled Epoxy-Coated Seven-Wire Prestressing Steel Strand. A882/A882M-04a. West Conshohocken, PA: ASTM International. https://doi.org/10.1520/A0882_A0882M-04AR10

ASTM. (2013). ASTM E917-05-13: Standard Practice for Measuring Life-Cycle Costs of Buildings and Building Systems.

ASTM. (2016). Standard Specification for Deformed and Plain Carbon-Steel Bars for Concrete Reinforcement. West Conshohocken, PA: ASTM International. https://doi.org/10.1520/A0615_A0615M-16

ASTM. (2017). Standard Specification for Solid Round Glass Fiber Reinforced Polymer Bars for Concrete Reinforcement. D7957/D7957M-17. West Conshohocken, PA: ASTM International. https://doi.org/10.1520/D7957_D7957M-17

ASTM. (2018). Specification for Low-Relaxation, Seven-Wire Steel Strand for Prestressed Concrete. ASTM A416/A416M-18. West Conshohocken, PA: ASTM International.

Benmokrane, B., \& Ali, A. H. (2016). Durability of FRP rebars in aggressive environments. In Proceedings of 8th International Conference on Fibre-Reinforced Polymer (FRP) Composites in Civil Engineering (CICE2016). 
Bentz, E., \& Thomas, M. D. A. (2018). Life-365 service life prediction model and Computer Program for Predicting the Service Life and Life-Cycle Cost of Reinforced Concrete Exposed to Chlorides. Version 2.2.3. Silica Fume Association.

Bertola, F., Canonico, F., \& Nanni, A. (2017). SEACON Project: sustainable concrete using seawater, saltcontaminated aggregates, and non-corrosive reinforcement. In XIV DBMC-14th International Conference on Durability of Building Materials and Components.

Biondini, F., \& Frangopol, D. M. (2016). Life-cycle performance of deteriorating structural systems under uncertainty. Journal of Structural Engineering, 142(9), F4016001.

Broadbent, C. (2016). Steel's recyclability: demonstrating the benefits of recycling steel to achieve a circular economy. International Journal of Life Cycle Assessment, 21(11), 1658-1665.

Brown, J., \& Tce, H. (2015). Glass Fibre Reinforced Polymer bars in Concrete Compression Members. In International Conference on Performance-Based and Life-Cycle Structural Engineering, School of Civil Engineering, The University of Queensland (pp. 1590-1599).

Cadenazzi, T., Dotelli, G., Rossini, M., Nolan, S., and A. Nanni. (2019a). Life-Cycle Cost and Life-Cycle Assessment Analysis at the Design Stage of a Fiber-Reinforced Polymer-Reinforced Concrete Bridge in Florida. Advances in Civil Engineering Materials. ASTM.

Cadenazzi, T., Nolan, S., Mazzocchi, G., Stringer, Z., and A. Nanni. (2019b). Bridge Case Study: What a Contractor Needs to Know on a FRP Reinforcement Project. ASCE Journal of Composites for Construction. (submitted).

Cadenazzi, T., Rossini, M., Dotelli, G., Nolan, S., Arrigoni, A. and A. Nanni. (2018). Resilience and Economical Sustainability of a FRP Reinforced Concrete Bridge in Florida: LCC Analysis at the Design Stage. The Sixth International Symposium on Life-Cycle Civil Engineering (IALCCE). Ghent, NE. (2018).

Capozucca, R. (1995). Damage to reinforced concrete due to reinforcement corrosion. Construction and Building Materials, 9(5), 295-303.

Ceroni, F., Cosenza, E., Gaetano, M., \& Pecce, M. (2006). Durability issues of FRP rebars in reinforced concrete members. Cement and concrete composites, 28(10), 857-868.

Correia, J. R., Almeida, N. M., \& Figueira, J. R. (2011). Recycling of FRP composites: reusing fine GFRP waste in concrete mixtures. Journal of Cleaner Production, 19(15), 1745-1753. 
Dehghan, A., Peterson, K., \& Shvarzman, A. (2017). Recycled glass fiber reinforced polymer additions to Portland cement concrete. Construction and Building Materials, 146, 238-250.

Eamon, C. D., Jensen, E. a., Grace, N. F., and Shi, X. (2012). “Life-Cycle Cost Analysis of Alternative Reinforcement Materials for Bridge Superstructures Considering Cost and Maintenance Uncertainties.” Journal of Materials in Civil Engineering, 24(4), 373-380.

EN, CEN. (2013). 15804: 2012+A1: 2013. Sustainability of Construction Works—Environmental Product Declarations-Core Rules for the Product Category of Construction Products.

FDOT (2015) - “Transportation Innovation Challenge” initiative (formally Invitation-to-Innovation), Florida Department of Transportation, Tallahassee, FL, USA. $2015 \quad$ - Present. https://www.fdot.gov/design/innovation/

FDOT. (2018a). Standard Specifications for Road and Bridge Construction: Section 346 - Portland Cement Concrete. Florida Department of Transportation.

FDOT. (2018b). Historical Cost. Program Management, Florida Department of Transportation. Retrieved from: https://www.fdot.gov/programmanagement/Estimates/HistoricalCostInformation/HistoricalCost.shtm

FDOT. (2019). Structures Design Guidelines - Structures Manual, Volume 1. Florida Department of Transportation.

Flint, G. N., \& Cox, R. N. (1988). The resistance of stainless steel partly embedded in concrete to corrosion by seawater. Magazine of concrete research, 40(142), 13-27.

Freire, L., Carmezim, M. J., Ferreira, M. A., \& Montemor, M. F. (2010). The passive behaviour of AISI 316 in alkaline media and the effect of pH: A combined electrochemical and analytical study. Electrochimica Acta, 55(21), 6174-6181.

García-Alonso, M. C., Escudero, M. L., Miranda, J. M., Vega, M. I., Capilla, F., Correia, M. J., ... \& González, J. A. (2007). Corrosion behaviour of new stainless steels reinforcing bars embedded in concrete. Cement and concrete research, 37(10), 1463-1471.

Gedge, G. (2008). Structural uses of stainless steel—buildings and civil engineering. Journal of constructional steel research, 64(11), 1194-1198.

Haghani, Reza, and Jincheng Yang. (2016). Application of FRP materials for construction of culvert road bridges: manufacturing and life-cycle cost analysis. Rapport 2016: 3. 
Hatami, A., \& Morcous, G. (2015). Deterministic and probabilistic lifecycle cost assessment: Applications to Nebraska bridges. Journal of Performance of Constructed Facilities, 30(2), 04015025.

International Organization for Standardization, ISO 14040:2006. (2006). Environmental management. Life cycle assessment -- Principles and framework.

International Organization for Standardization, ISO 14044:2006. (2206). Environmental management. Life cycle assessment -- Requirements and guidelines

International Organization for Standardization. ISO 21930:2017. (2017). Sustainability in buildings and civil engineering works - Core rules for environmental product declarations of construction products and services.

ISO 15686-5. (2008). Buildings and constructed assets-Service-life planning-Part 5: Life-cycle costing. International Organization for Standardization.

Japan Society of Civil Engineering, JSCE. (2007). Standard specification for concrete structures-Materials and construction. JSCE-Guidelines for Concrete 16. Tokyo: Japan Society of Civil Engineering (JSCE).

Jin, W. L., Yan, Y. D., \& Wang, H. L. (2010). Chloride diffusion in the cracked concrete. Fracture Mechanics of Concrete and Concrete Structures-Assessment, Durability, Monitoring and Retrofitting, 880-886.

Kere, K. J., \& Huang, Q. (2019). Life-Cycle Cost Comparison of Corrosion Management Strategies for Steel Bridges. Journal of Bridge Engineering, 24(4), 04019007.

Lindquist, W. D., Darwin, D., Browning, J., \& Miller, G. G. (2006). Effect of cracking on chloride content in concrete bridge decks. American Concrete Institute.

Mistry, Mark, Christoph Koffler, and Sophia Wong. (2016). LCA and LCC of the world's longest pier: a case study on nickel-containing stainless steel bar. The International Journal of Life Cycle Assessment 21, no. 11: 16371644.

Moschetti, R., \& Brattebø, H. (2017). Combining life cycle environmental and economic assessments in building energy renovation projects. Energies, 10(11), 1851.

Moser, R.D., Singh, P., Kahn, L.F., and Kurtis, K.E. (2012). "Durability of Precast Prestressed Concrete Piles in Marine Environment, Part 2 Volume 2: Stainless Steel Prestressing Strand and Wire,” Georgia Institute of Technology, Atlanta, GA.

Page 31 of 52 
Office of Management and Budget. (2017). Circular A-94 Appendix C: Discount Rates for Cost-Effectiveness, Lease Purchase, and Related Analyses. Washington D.C. Retrieved from: https://www.whitehouse.gov/wpcontent/uploads/2017/11/Appendix-C.pdf

Ping, G., Elliott, S., Beaudoin, J. J., \& Arsenault, B. (1996). Corrosion resistance of stainless steel in chloride contaminated concrete. Cement and Concrete Research, 26(8), 1151-1156.

Redaelli, E., Arrigoni, A., Carsana, M., Dotelli, G., Gastaldi, M., Lollini, F., Bertola, F., Canonico, F., and Nanni, A. (2019). Culvert Prototype Made with Seawater Concrete: Materials Characterization, Monitoring, and Environmental Impact, Advances in Civil Engineering Materials, https://doi.org/10.1520/ACEM20180114. ISSN 2379-1357.

Ristimäki, M., Säynäjoki, A., Heinonen, J., \& Junnila, S. (2013). Combining life cycle costing and life cycle assessment for an analysis of a new residential district energy system design. Energy, 63, 168-179.

Robert, M., Cousin, P., \& Benmokrane, B. (2009). Durability of GFRP reinforcing bars embedded in moist concrete. Journal of Composites for Construction, 13(2), 66-73.

Rossini, M., Cadenazzi, T., Nolan, S., \& Nanni, A. (2018). SEACON and Resilient FRP-RC/PC Solutions: The Halls River Bridge. Italian Concrete Days.

Sagues, A. \& Mullins, G. (2018). Quantifying the Duration of the Corrosion Propagation Stage in Stainless Steel Reinforcement - Research Project BDV25 977-56 for Florida Department of Transportation, 2018-2020.

Sagüés, A. A., Lee, J. B., Chang, X., Pickering, H., Nystrom, E., Carpenter, W., ... \& Hierholzer, S. (1994). Corrosion of Epoxy-Coated Rebar in Florida Bridges. reporte final al FDOT, WPI, (0510603).

Sajedi, S., \& Huang, Q. (2019). Reliability-based life-cycle-cost comparison of different corrosion management strategies. Engineering Structures, 186, 52-63.

Sedriks, A. J. (1996). Corrosion of stainless steel, $2^{\text {nd }}$ edition. United States.

Sharp, S. R., Ozyildirim, H. C., \& Moruza, A. K. (2019). Corrosion-Free Carbon Fiber Reinforced Polymer for Prestressed Piles (No. FHWA/VTRC 19-R13).

Shepard, R. W. (2005). Bridge management issues in a large agency. Structure and Infrastructure Engineering, 1(2), 159-164.

Silica Fume Association. (2017). Life-365 v.2.2.3 [computer software]. Retrieved from: http://www.life-365.org 
Spadea, S., Rossini, M., \& Nanni, A. (2018). Design Analysis and Experimental Behavior of Precast Concrete DoubleTee Girders Prestressed with Carbon-Fiber-Reinforced Polymer Strands. PCI Journal, 63(1), 72-84. Retrieved from $\quad$ https://www.pci.org/PCI/Publications/PCI_Journal/Issues/2018/JanuaryFebruary/Design_analysis_and_experimental_behavior_of_precast_concrete_doubletee_girders_prestressed.aspx

Srensen, B., Jensen, P. B., \& Maahn, E. (1990). The corrosion properties of stainless steel reinforcement. Corrosion of reinforcement in concrete, 601-610.

Tanaka, Y., Kawano, H., Watanabe, H., \& Nakajo, T. (2006). Study on cover depth for prestressed concrete bridges in airborne-chloride environments. PCI journal, 51(2), 42.

Veleva, L., Alpuche-Aviles, M. A., Graves-Brook, M. K., \& Wipf, D. O. (2002). Comparative cyclic voltammetry and surface analysis of passive films grown on stainless steel 316 in concrete pore model solutions. Journal of Electroanalytical Chemistry, 537(1-2), 85-93.

Xie, H. B., Wang, Y. F., Gong, J., Liu, M. H., \& Yang, X. Y. (2018). Effect of global warming on chloride ion erosion risks for offshore RC bridges in China. KSCE Journal of Civil Engineering, 22(9), 3600-3606.

Xie, H.-B., Wu, W.-J., \& Wang, Y.-F. (2018). Life-time reliability based optimization of bridge maintenance strategy considering LCA and LCC. Journal of Cleaner Production, 176, 36-45.

Yang, D. Y., Frangopol, D. M., \& Teng, J. G. (2019). Probabilistic life-cycle optimization of durability-enhancing maintenance actions: Application to FRP strengthening planning. Engineering Structures, 188, 340-349.

Yazdanbakhsh, A., \& Bank, L. (2014). A critical review of research on reuse of mechanically recycled FRP production and end-of-life waste for construction. Polymers, 6(6), 1810-1826.

Younis, A., Ebead, U., and Judd, S. (2018). "Life cycle cost analysis of structural concrete using seawater, recycled concrete aggregate, and GFRP reinforcement.” Construction and Building Materials, 175, 152-160. 


\section{List of Tables}

1. Alternative reinforcement cost comparisons

2. ECS-RC/PC construction costs

3. SS-RC/PC construction costs

4. Maintenance and Repair Costs

5. LCC results

6. Environmental impacts: Cradle-to-gate

7. Environmental impacts: Cradle-to-grave

8. Sensitivity Analysis: Cost Variance of Reinforcement

9. Sensitivity Analysis: Chloride Concentration 


\section{List of Figures}

1. Halls River Bridge aerial picture as of December 2018

2. Chloride concentration threshold at 6 years, for $76.2 \mathrm{~mm}$ of concrete cover (a); Chloride Concentration over time at depth $76.2 \mathrm{~mm}$ for CS-RC/PC and ECS-RC/PC (b)

3. Conceptual Durability Performance of CS-RC/PC and ECS-RC/PC solutions (a); Conceptual Durability Performance of FRP-RC/PC and SS-RC/PC solutions (b)

4. Chloride Concentration over time at depth $50.8 \mathrm{~mm}$ for SS-RC/PC

5. Life cycle stages of design alternatives

6. LCC results considering the baseline scenario where discount rate is $1 \%$

7. Breakdown of Life-Cycle Cost for each alternative (discount rate 1\%)

8. LCA Results: Global Warming

9. LCA Results: Photochemical Oxidant Creation

10. Sensitivity analysis of LCC results to the discount rate

11. US Midwest Domestic Hot-Rolled Coil Steel Monthly Price (2009-2019)

12. Sensitivity analysis of LCC results to the Cost of Reinforcement

13. Variation of Chloride Concentration over time at depth $76.2 \mathrm{~mm}$ for CS-RC/PC and ECS-RC/PC

14. Sensitivity analysis of LCC results to the Variation of Chloride Concentration 


\section{TABLES}

TABLE 1 - Alternative reinforcement cost comparisons

\begin{tabular}{|c|c|c|c|c|c|c|c|c|c|c|}
\hline \multicolumn{11}{|c|}{ Reinforcing bars } \\
\hline \multirow[b]{2}{*}{ Bar size } & \multicolumn{2}{|c|}{ Carbon steel } & \multicolumn{2}{|c|}{ GFRP } & \multicolumn{2}{|c|}{ ECS } & \multicolumn{2}{|c|}{ SS } & \multicolumn{2}{|c|}{ CFRP } \\
\hline & $\begin{array}{c}\text { Unit } \\
\text { weight } \\
\text { [kg/m] }\end{array}$ & $\begin{array}{c}\text { Cost } \\
{[\mathrm{USD} / \mathrm{m}]}\end{array}$ & $\begin{array}{c}\text { Unit } \\
\text { weight } \\
\text { [kg/m] }\end{array}$ & $\begin{array}{c}\text { Cost } \\
{[\mathrm{USD} / \mathrm{m}]}\end{array}$ & $\begin{array}{c}\text { Unit } \\
\text { weight } \\
\text { [kg/m] }\end{array}$ & $\begin{array}{c}\text { Cost } \\
{[\mathrm{USD} / \mathrm{m}]}\end{array}$ & $\begin{array}{c}\text { Unit } \\
\text { weight } \\
\text { [kg/m] }\end{array}$ & $\begin{array}{c}\text { Cost } \\
{[\mathrm{USD} / \mathrm{m}]}\end{array}$ & $\begin{array}{c}\text { Unit } \\
\text { weight } \\
\text { [kg/m] }\end{array}$ & $\begin{array}{c}\text { Cost } \\
{[\mathrm{USD} / \mathrm{m}]}\end{array}$ \\
\hline M10 & 0.561 & 0.75 & 0.159 & 1.71 & 0.561 & 1.00 & 0.561 & 4.93 & N/A & N/A \\
\hline M13 & 0.996 & 1.31 & 0.281 & 2.36 & 0.996 & 1.75 & 0.996 & 8.79 & N/A & N/A \\
\hline M16 & 1.556 & 2.07 & 0.427 & 3.80 & 1.556 & 2.75 & 1.556 & 13.69 & N/A & N/A \\
\hline M19 & 2.240 & 2.95 & 0.607 & 4.99 & 2.240 & 3.93 & 2.240 & 19.71 & N/A & N/A \\
\hline M25 & 3.982 & 5.25 & 1.046 & 8.56 & 3.982 & 6.98 & 3.982 & 35.04 & N/A & N/A \\
\hline $\begin{array}{c}1 \times 7 \\
15.2 \mathrm{~mm} \\
\text { strand }\end{array}$ & 1.210 & 3.30 & N/A & N/A & 1.210 & 4.39 & 1.210 & 22.01 & $\begin{array}{c}0.22 \\
1\end{array}$ & 12.50 \\
\hline
\end{tabular}

TABLE 2 - ECS-RC/PC construction costs

\begin{tabular}{|c|c|c|c|c|c|c|c|}
\hline Item & $\begin{array}{r}\text { Prod } \\
{[A}\end{array}$ & $\begin{array}{l}\text { Ict stage } \\
\text { [-A3] }\end{array}$ & $\begin{array}{c}\text { Transport to job site } \\
\text { [A4] }\end{array}$ & Constr & Iction [A5] & & Total \\
\hline Sheet piles & USD & 935,587 & USD 169,200 & USD & 332,516 & USD & $1,437,303$ \\
\hline Piles & USD & 250,292 & USD $\quad 31,104$ & USD & 223,700 & USD & 505,097 \\
\hline Bulkhead caps & USD & 22,480 & Included at product & USD & 33,412 & USD & 55,891 \\
\hline Pier/pier caps & USD & 50,222 & Included at product & USD & 167,577 & USD & 217,799 \\
\hline Girders & USD & 153,111 & 8,775 & USD & 115,694 & USD & 277,580 \\
\hline Deck & USD & 126,344 & Included at product & USD & 269,223 & USD & 395,568 \\
\hline Approach slabs & USD & 29,527 & Included at product & USD & 59,612 & USD & 89,139 \\
\hline Traffic railing & USD & 20,679 & Included at product & USD & 24,534 & USD & 45,213 \\
\hline Gravity wall & USD & 3,431 & Included at product & USD & 23,877 & USD & 27,309 \\
\hline & & & \multicolumn{3}{|c|}{ Total ECS-RC/PC structures } & \multicolumn{2}{|c|}{ USD $\mathbf{3 , 0 5 0 , 8 9 7}$} \\
\hline
\end{tabular}

TABLE 3 - SS-RC/PC construction costs

\begin{tabular}{|c|c|c|c|c|}
\hline Item & $\begin{array}{c}\text { Product stage } \\
\text { [A1-A3] }\end{array}$ & $\begin{array}{c}\text { Transport to job site } \\
\text { [A4] }\end{array}$ & Construction [A5] & Total \\
\hline Sheet piling & USD $1,065,371$ & USD 169,200 & USD 332,516 & USD $1,567,087$ \\
\hline Piling & USD $\quad 287,921$ & USD 31,104 & USD 223,700 & 542,725 \\
\hline Bulkhead caps & USD $\quad 46,675$ & 0 & 33,412 & 80,087 \\
\hline Pier/pier caps & 127,229 & 0 & USD 167,577 & 294,806 \\
\hline Girders & 492,104 & USD $\quad 8,775$ & USD 115,694 & 616,573 \\
\hline Deck & 467,548 & 0 & USD 269,223 & 736,771 \\
\hline Approach slabs & 80,774 & 0 & 59,612 & 140,385 \\
\hline Traffic railing & 60,943 & 0 & 24,534 & 85,477 \\
\hline Gravity wall & 5,735 & 0 & 23,877 & 29,612 \\
\hline & & \multicolumn{2}{|c|}{ Total SS-RC/PC structures } & USD 4,093,525 \\
\hline
\end{tabular}


TABLE 4 - Maintenance and Repair Costs

\begin{tabular}{|c|c|c|c|c|}
\hline \multicolumn{5}{|c|}{ Maintenance/Repair activities cost } \\
\hline Activity & FRP-RC/PC; SS-RC/PC & ECS-RC/PC & & CS-RC/PC \\
\hline Concrete patching & USD 21,781 & $\begin{array}{rr}\text { First time: USD } & 21,781 \\
\text { Every other year: USD } & 61,214\end{array}$ & USD & 61,214 \\
\hline CP1 + bulkhead reinforcement replacement & - & USD 418,340 & USD & 418,340 \\
\hline CP2 & - & USD 274,538 & USD & 274,538 \\
\hline $\mathrm{CP} 3$ & - & USD $\quad 274,538$ & USD & 274,538 \\
\hline $\begin{array}{l}\text { CP1 removal and re-installation + bulkhead } \\
\text { reinforcement replacement }\end{array}$ & - & 454,340 & USD & 454,340 \\
\hline CP2 removal and re-installation & & USD 310,538 & USD & 310,538 \\
\hline Demolition & USD 573,352 & USD $\quad 573,352$ & USD & 573,352 \\
\hline Reconstruction & - & USD $5,739,842$ & USD & $5,514,278$ \\
\hline Recycling & USD 167,633 & USD 197,721 & USD & 197,721 \\
\hline \multicolumn{5}{|c|}{ Maintenance/Repair activities cost breakdown by year (discount rate assumed 1\%) } \\
\hline Year & FRP-RC/PC; SS-RC/PC & ECS-RC/PC & \multicolumn{2}{|c|}{ CS-RC/PC } \\
\hline 11 & USD 19,523 & USD $\quad 19,523$ & USD & 54,867 \\
\hline 21 & USD 17,674 & 49,671 & USD & 49,671 \\
\hline 31 & USD 16,000 & 44,966 & USD & 307,303 \\
\hline 41 & USD 14,485 & USD $\quad 40,707$ & USD & 182,569 \\
\hline 45 & - & USD $\quad 267,342$ & & - \\
\hline 51 & USD 13,113 & - & USD & 165,277 \\
\hline 55 & - & USD $\quad 158,828$ & USD & 160,416 \\
\hline 56 & - & - & USD & 260,246 \\
\hline 61 & USD 11,871 & & USD & 33,361 \\
\hline 65 & - & USD 143,785 & USD & 145,223 \\
\hline 66 & - & - & USD & 161,029 \\
\hline 70 & - & USD $\quad 208,465$ & & - \\
\hline 71 & USD 10,746 & - & USD & 30,504 \\
\hline 75 & - & USD $1,178,986$ & USD & $1,143,337$ \\
\hline 76 & - & (USD 93,745$)$ & (USD & $93,745)$ \\
\hline 81 & USD 9,729 & - & & - \\
\hline 86 & - & 9,256 & USD & 26,014 \\
\hline 91 & USD 8,807 & - & & \\
\hline 96 & - & 23,550 & USD & 23,550 \\
\hline 100 & USD 211,975 & - & & - \\
\hline 101 & (USD 61,976) & (USD 135,075) & & - \\
\hline
\end{tabular}

Table 5 - LCC results

\begin{tabular}{|c|c|c|c|c|}
\hline \multicolumn{5}{|c|}{ RESULTS } \\
\hline & CS-RC/PC BRIDGE & FRP-RC/PC BRIDGE & ECS-RC/PC BRIDGE & SS-RC/PC BRIDGE \\
\hline Net Present Value (NPV) & USD 7,858,262 & USD $6,287,592$ & USD 7,791,177 & USD 7,043,293 \\
\hline Net Saving (NS) & & USD $1,570,670$ & USD $\quad 67,085$ & USD $\quad 814,969$ \\
\hline "Annual Savings (AS) & & 15,707 & USD & 8,149 \\
\hline
\end{tabular}

Table 6 - Environmental impacts: from-cradle-to-gate scenario

\begin{tabular}{|cccccc|}
\hline \multicolumn{5}{c|}{ Cradle-to-Gate Results } \\
\hline Impact category & Unit of Measure & CS-RC/PC & ECS-RC/PC & FRP-RC/PC & SS-RC/PC \\
Ozone depletion & $\mathrm{kg} \mathrm{CFC-11} \mathrm{eq.}$ & 0.0844 & 0.0844 & 0.5237 & 0.0886 \\
Global warming & $\mathrm{kg} \mathrm{CO} 2$ eq. & $1,052,839$ & $1,082,190$ & $1,048,043$ & $1,063,562$ \\
$\begin{array}{c}\text { Photochemical } \\
\text { oxidant creation }\end{array}$ & $\mathrm{kg} \mathrm{O}_{3}$ eq. & 57,960 & 61,753 & 66,856 & 62,543 \\
Acidification & $\mathrm{kg} \mathrm{SO}_{2}$ eq. & 4,021 & 4,213 & 5,172 & 4,489 \\
\hline
\end{tabular}




\begin{tabular}{|llllll|}
\hline Eutrophication & kg N eq. & 2,541 & 2,569 & 1,706 & 2,663 \\
\hline
\end{tabular}

Table 7 - Environmental impacts: from-cradle-to-grave scenario

\begin{tabular}{|cccccc|}
\hline \multicolumn{5}{c|}{ Cradle-to-Grave Results } \\
\hline Impact category & Unit of Measure & CS-RC/PC & ECS-RC/PC & FRP-RC/PC & SS-RC/PC \\
Ozone depletion & kg CFC-11 eq. & 0.1253 & 0.1253 & 0.5343 & 0.1007 \\
Global warming & kg CO 2 eq. & $1,475,687$ & $1,512,690$ & $1,091,039$ & $1,126,547$ \\
$\begin{array}{c}\text { Photochemical } \\
\text { oxidant creation }\end{array}$ & $\mathrm{kg} \mathrm{O}_{3}$ eq. & 83,542 & 88,559 & 71,666 & 68,555 \\
$\begin{array}{cccc}\text { Acidification } \\
\text { Eutrophication }\end{array}$ & $\mathrm{kg} \mathrm{SO}_{2}$ eq. & 5,682 & 5,932 & 5,389 & 4,786 \\
\hline
\end{tabular}

Table 8 - Sensitivity Analysis: Cost Variance of Reinforcement

\begin{tabular}{|ccccc|}
\hline \multicolumn{7}{c}{ SENSITIVITY ANALYSIS - COST VARIANCE OF REINFORCEMENT } & \\
\hline VARIANCE & CS-RC/PC BRIDGE & FRP-RC/PC BRIDGE & ECS-RC/PC BRIDGE & SS-RC/PC BRIDGE \\
\hline$-18 \%$ & USD 7,611,362 & USD 5,951,446 & USD 7,503,676 & USD 6,569,119 \\
$-15 \%$ & USD 7,652,346 & USD 6,007,470 & USD 7,551,426 & USD 6,648,148 \\
\hline$-12 \%$ & USD 7,693,529 & USD 6,063,495 & USD 7,599,376 & USD 6,727,177 \\
$-9 \%$ & USD 7,734,712 & USD 6,119,519 & USD 7,647,326 & USD 6,806,206 \\
$-6 \%$ & USD 7,775,896 & USD 6,175,543 & USD 7,695,277 & USD 6,885,235 \\
$-3 \%$ & USD 7,817,079 & USD 6,231,568 & USD 7,743,227 & USD 6,964,264 \\
\hline $0 \%$ & USD 7,858,262 & USD 6,287,592 & USD 7,791,177 & USD 7,043,293 \\
\hline $3 \%$ & USD 7,899,446 & USD 6,343,616 & USD 7,839,127 & USD 7,122,322 \\
\hline $6 \%$ & USD 7,940,629 & USD 6,399,641 & USD 7,887,078 & USD 7,201,351 \\
$9 \%$ & USD 7,981,812 & USD 6,455,665 & USD 7,935,028 & USD 7,280,380 \\
\hline $12 \%$ & USD 8,022,996 & USD 6,511,689 & USD 7,982,978 & USD 7,359,409 \\
\hline $15 \%$ & USD 8,064,179 & USD 6,567,714 & USD 8,030,928 & USD 7,438,438 \\
\hline $18 \%$ & USD 8,105,162 & USD 6,623,738 & USD 8,078,678 & USD 7,517,467 \\
\hline \hline Standard Deviation & USD 148,461 & USD 201,999 & USD 172,859 & USD 284,943 \\
\hline Coefficient of Variation & $\mathbf{1 . 8 8 \%}$ & $\mathbf{3 . 2 0 \%}$ & $\mathbf{2 . 2 1 \%}$ & $\mathbf{4 . 0 2 \%}$ \\
\hline
\end{tabular}

Table 9 - Sensitivity Analysis: Chloride Concentration

\begin{tabular}{|c|c|c|c|c|c|c|c|c|}
\hline \multicolumn{9}{|c|}{ SENSITIVITY ANALYSIS - CHLORIDE CONCENTRATION } \\
\hline \multirow{2}{*}{$\begin{array}{c}\text { VARIABILITY } \\
0 \%\end{array}$} & \multicolumn{2}{|c|}{ CS-RC/PC BRIDGE } & \multicolumn{2}{|c|}{ FRP-RC/PC BRIDGE } & \multicolumn{2}{|c|}{ ECS-RC/PC BRIDGE } & \multicolumn{2}{|c|}{ SS-RC/PC BRIDGE } \\
\hline & USD & $7,858,262$ & \multirow{3}{*}{ USD } & \multirow{3}{*}{$6,287,592$} & USD & $7,791,177$ & \multirow{3}{*}{ USD } & \multirow{3}{*}{$7,043,293$} \\
\hline $6 \%$ & USD & $7,869,924$ & & & USD & $7,801,383$ & & \\
\hline $15 \%$ & USD & $7,881,939$ & & & USD & $7,811,898$ & & \\
\hline Cost Range & USD & 11,662 & & - & USD & 10,206 & & - \\
\hline Standard Deviation & USD & 11,839 & & - & USD & 10,361 & & - \\
\hline
\end{tabular}




\section{FIGURES}

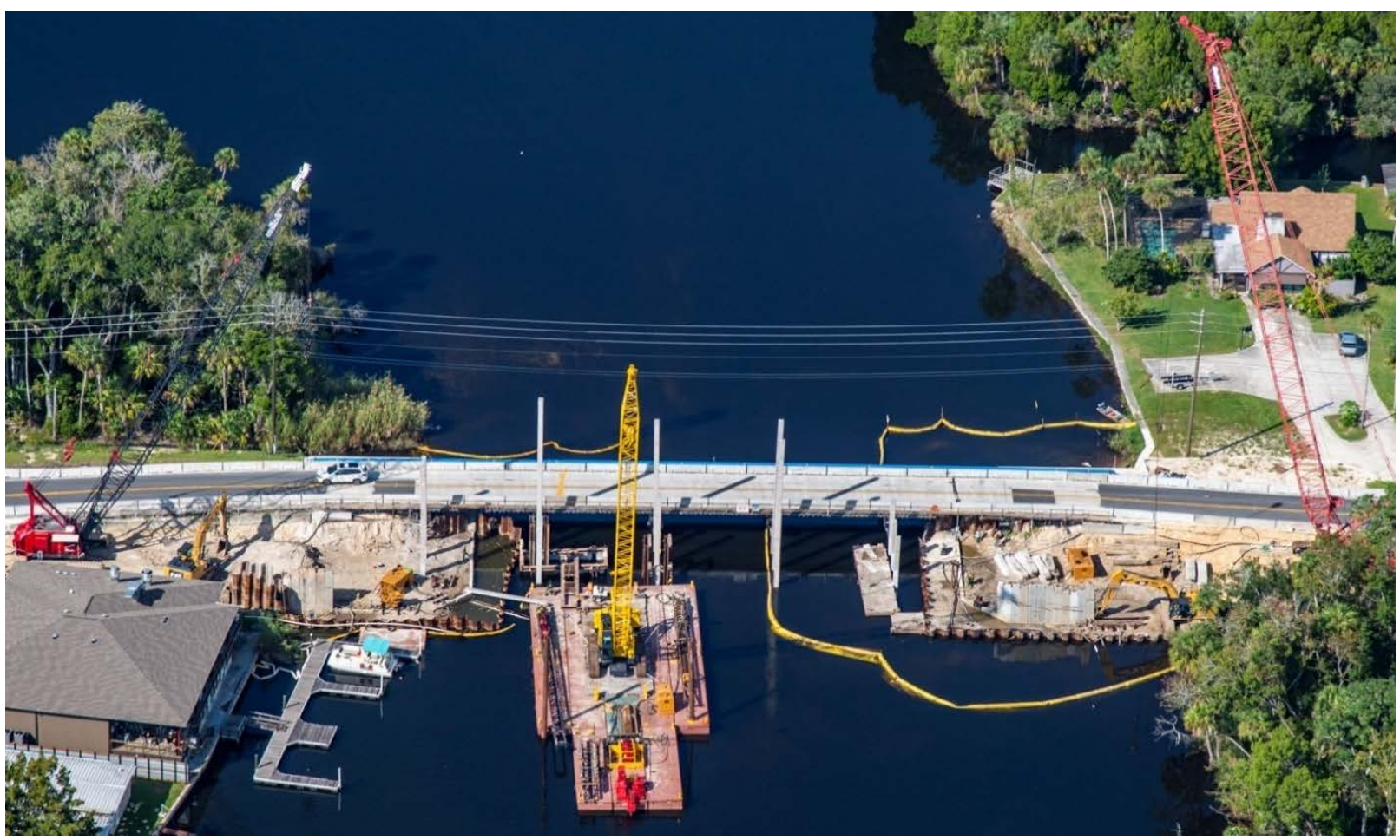

Figure 1 - Halls River Bridge aerial picture as of December 2018 
Figure 2 - Chloride concentration threshold at 12 years, for $76.2 \mathrm{~mm}$ of concrete cover (a); Chloride Concentration over time at depth $76.2 \mathrm{~mm}$ for CS-RC/PC and ECS-RC/PC (b) 


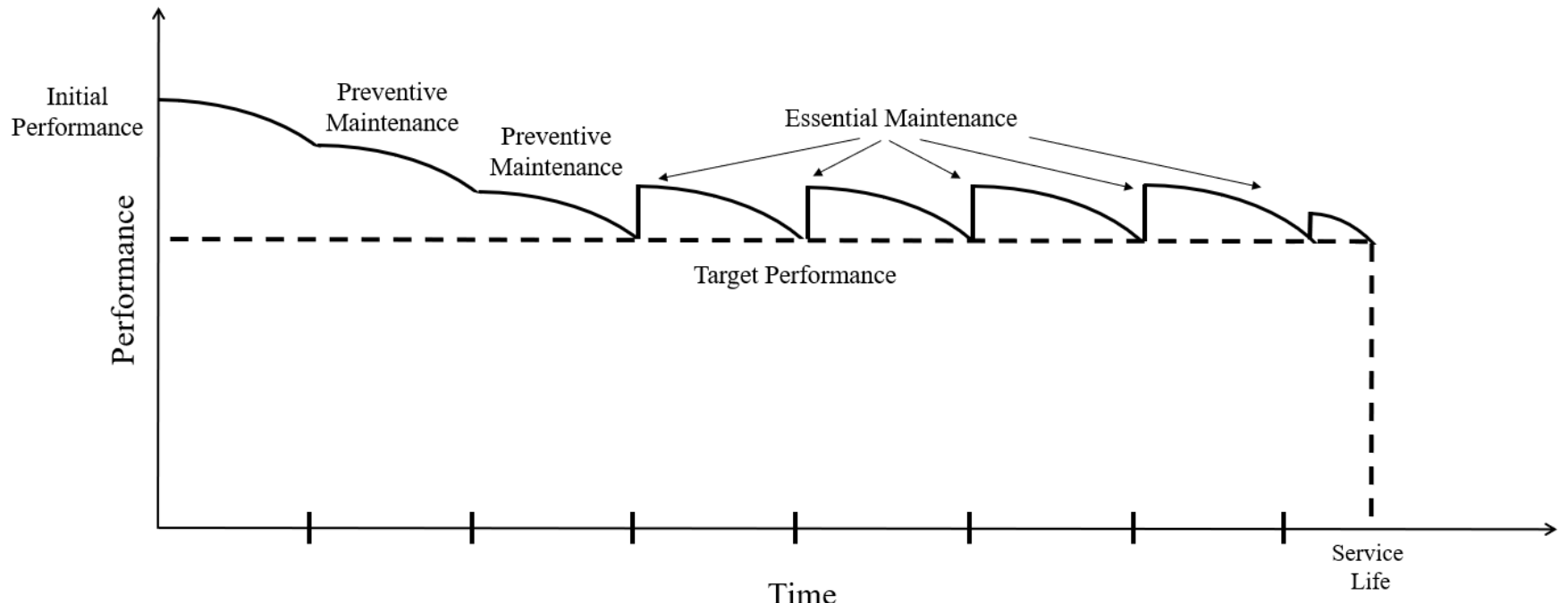

(a)

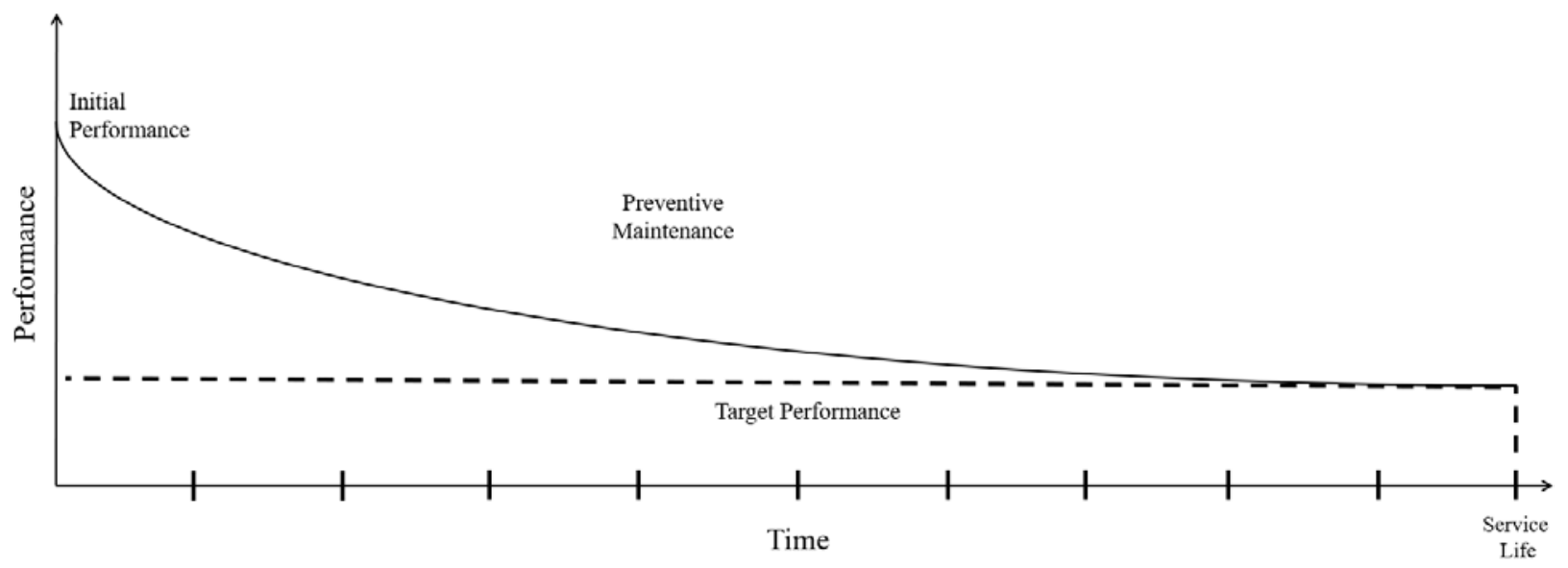

(b)

Figure 3 - Conceptual Durability Performance of CS-RC/PC and ECS-RC/PC solutions (a); Conceptual Durability Performance of FRP-RC/PC and SS-RC/PC solutions (b) 


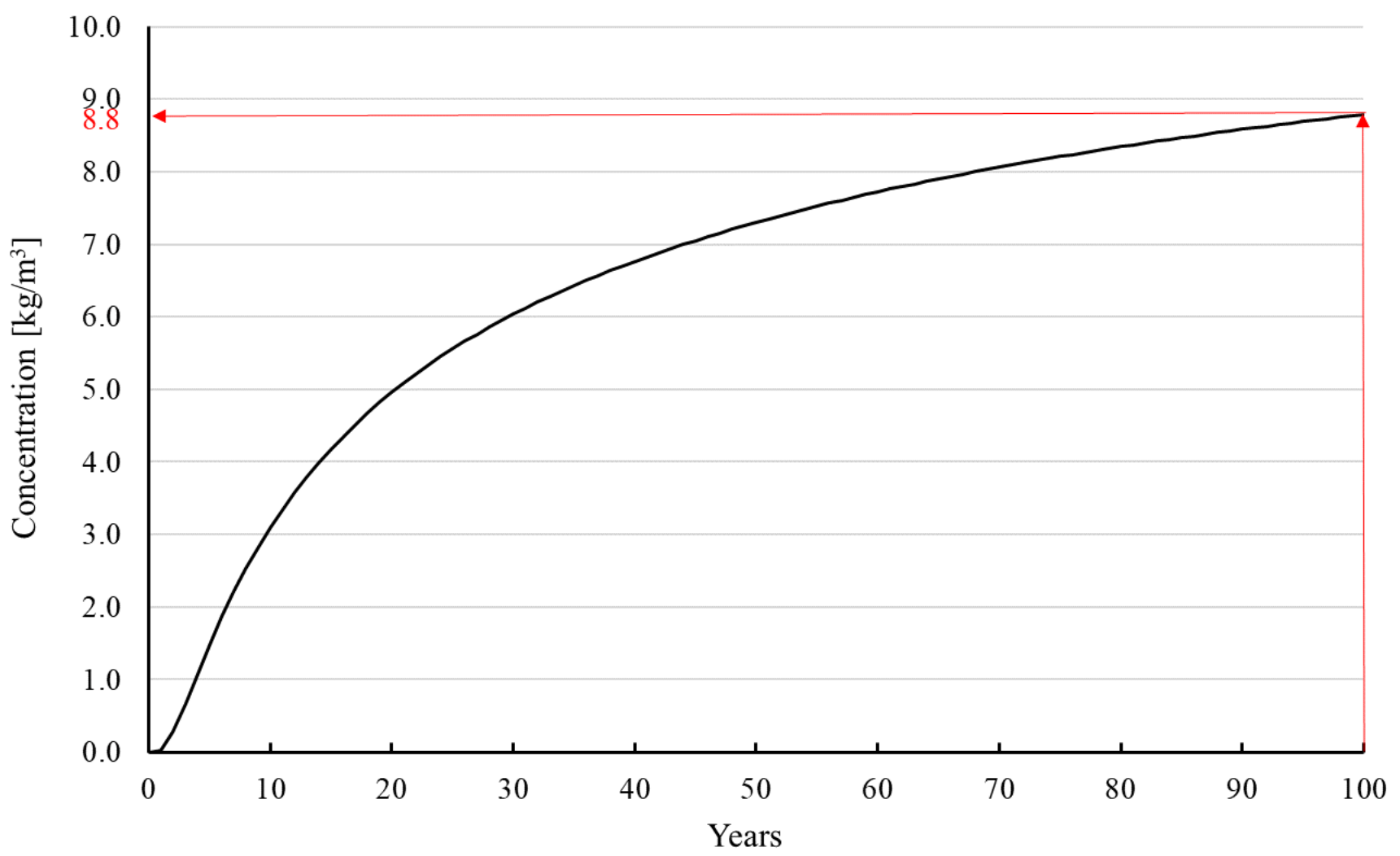

Figure 4 - Chloride Concentration over time at depth $50.8 \mathrm{~mm}$ for SS-RC/PC 


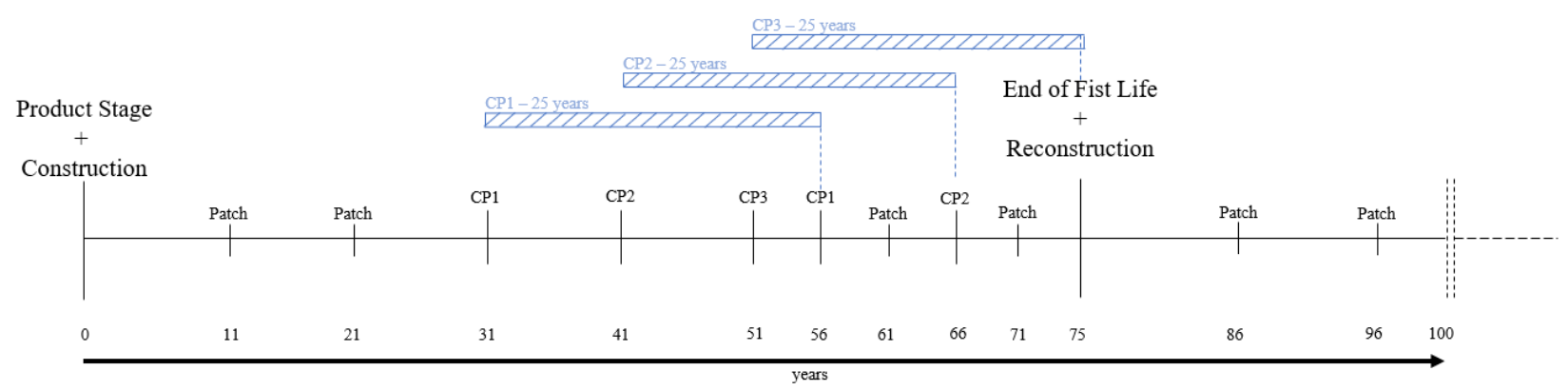

CS-RC/PC alternative

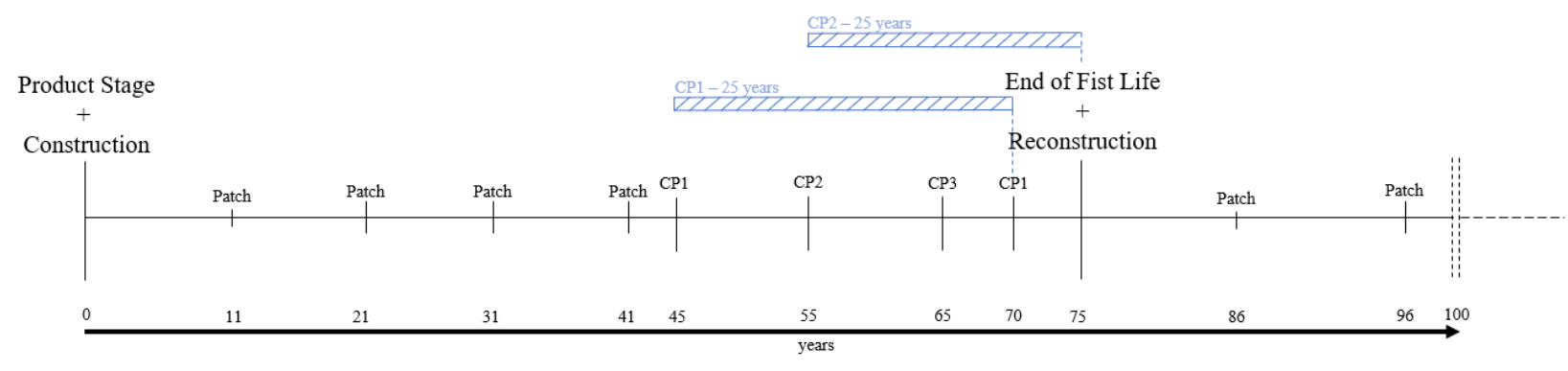

EC-RC/PC alternative

Product Stage

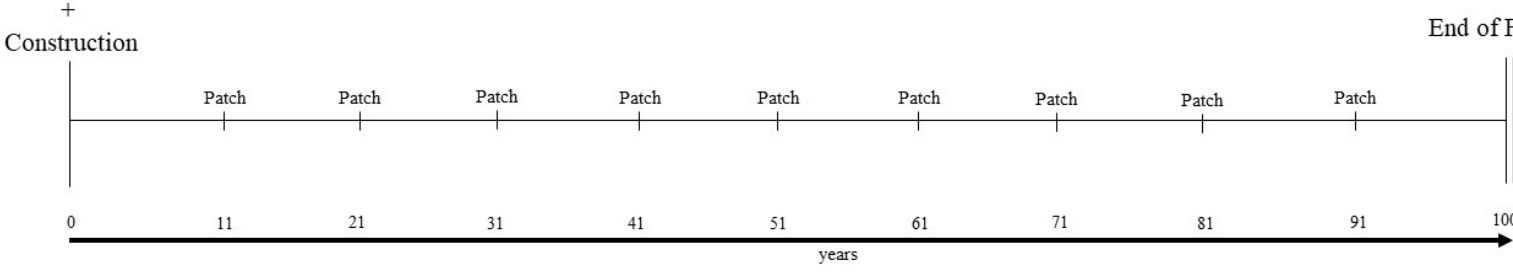

SS-RC/PC alternative

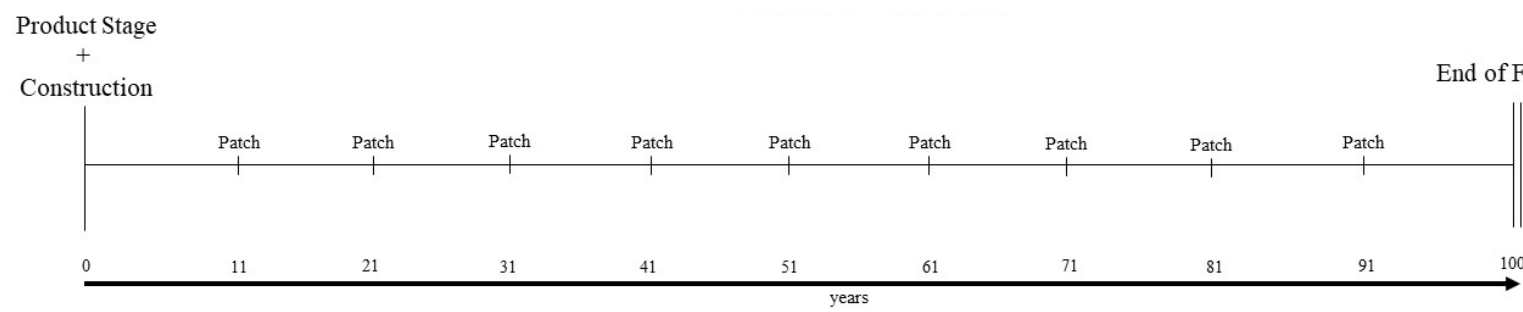

FRP-RC/PC Alternative

Figure 5 - Life cycle stages of design alternatives 


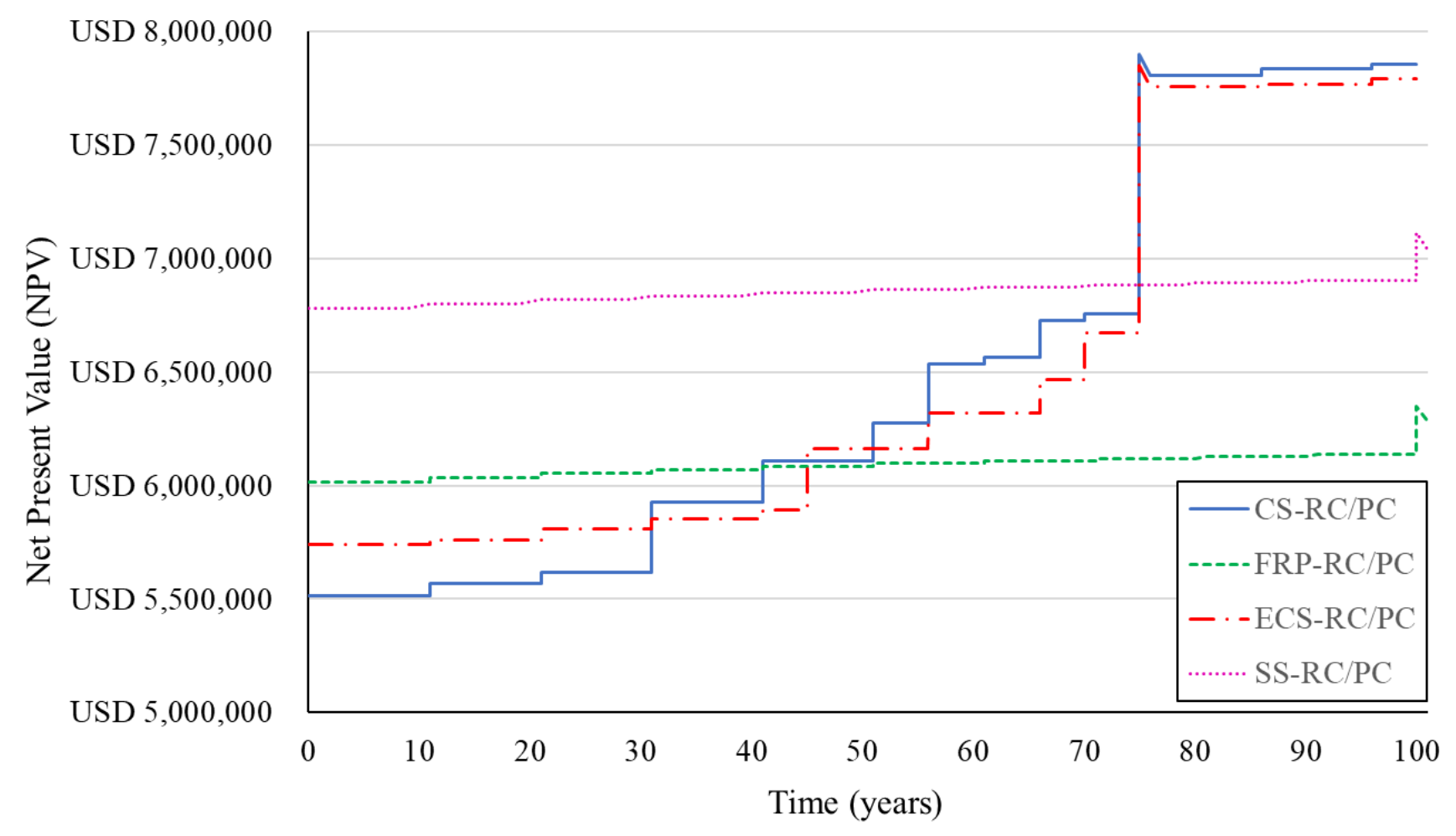

Figure 6 - LCC results considering the baseline scenario where discount rate is $1 \%$ 


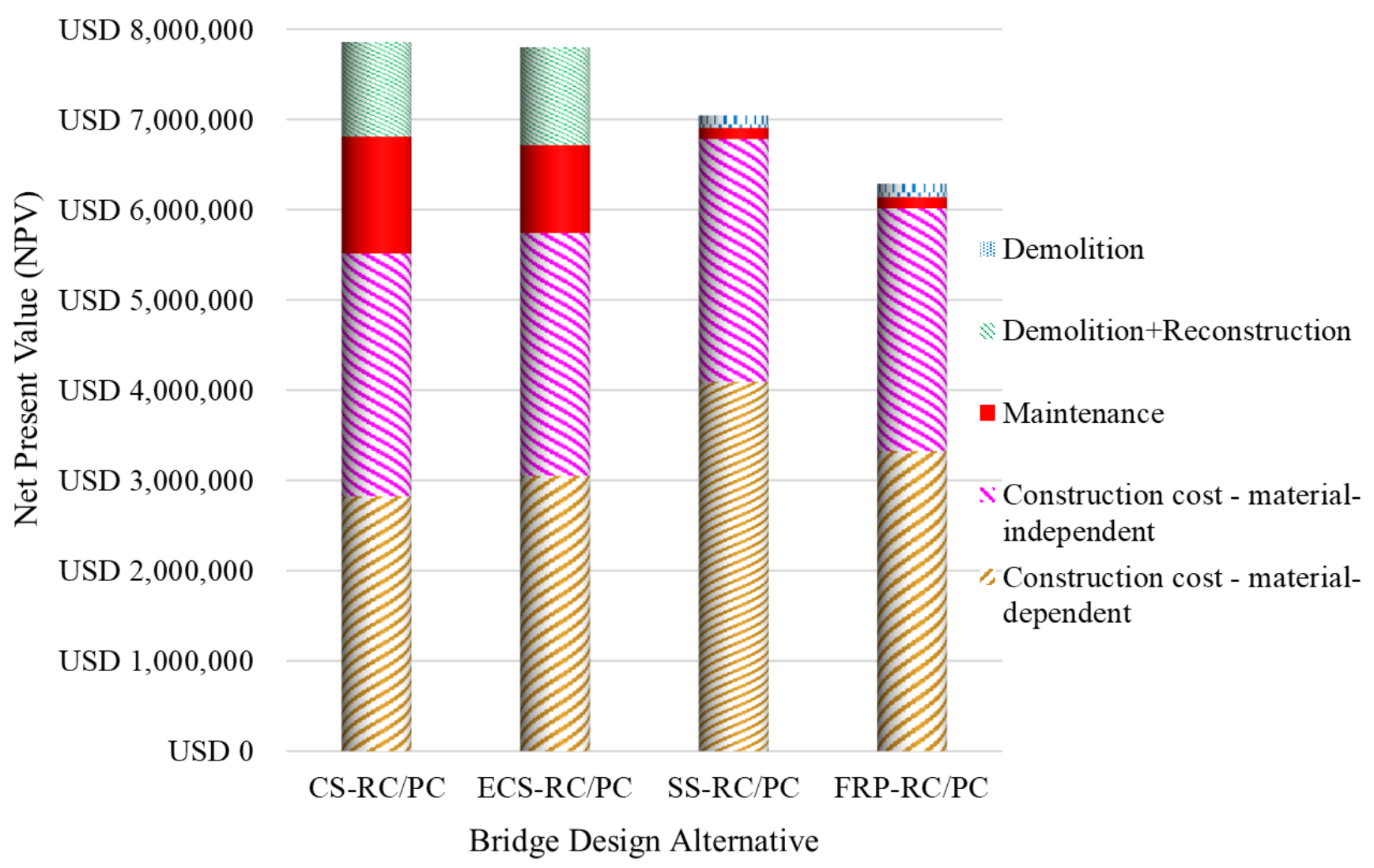

Figure 7 - Breakdown of Life-Cycle Cost for each alternative (discount rate 1\%) 


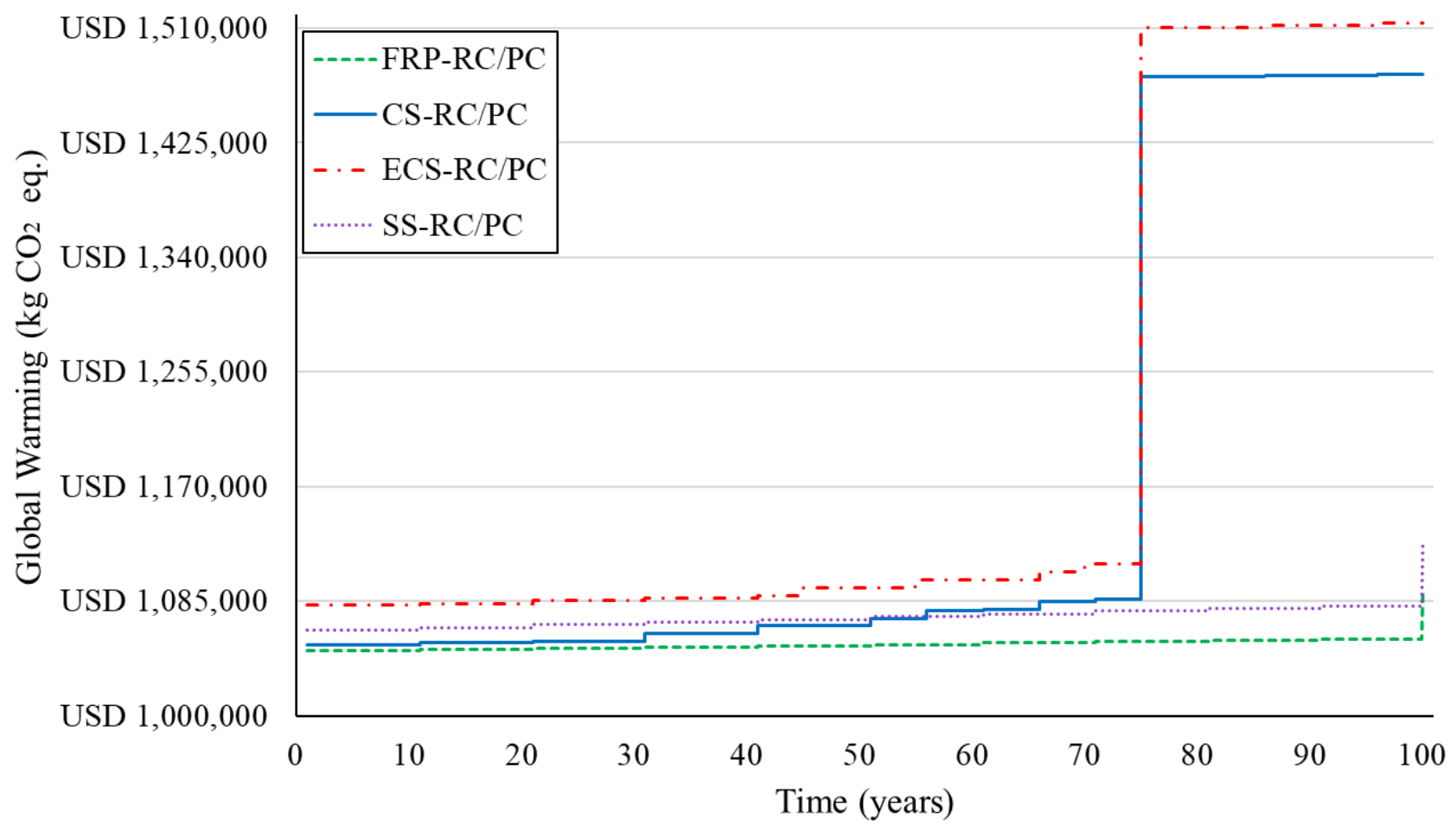

Figure 8 - LCIA results: Global Warming 


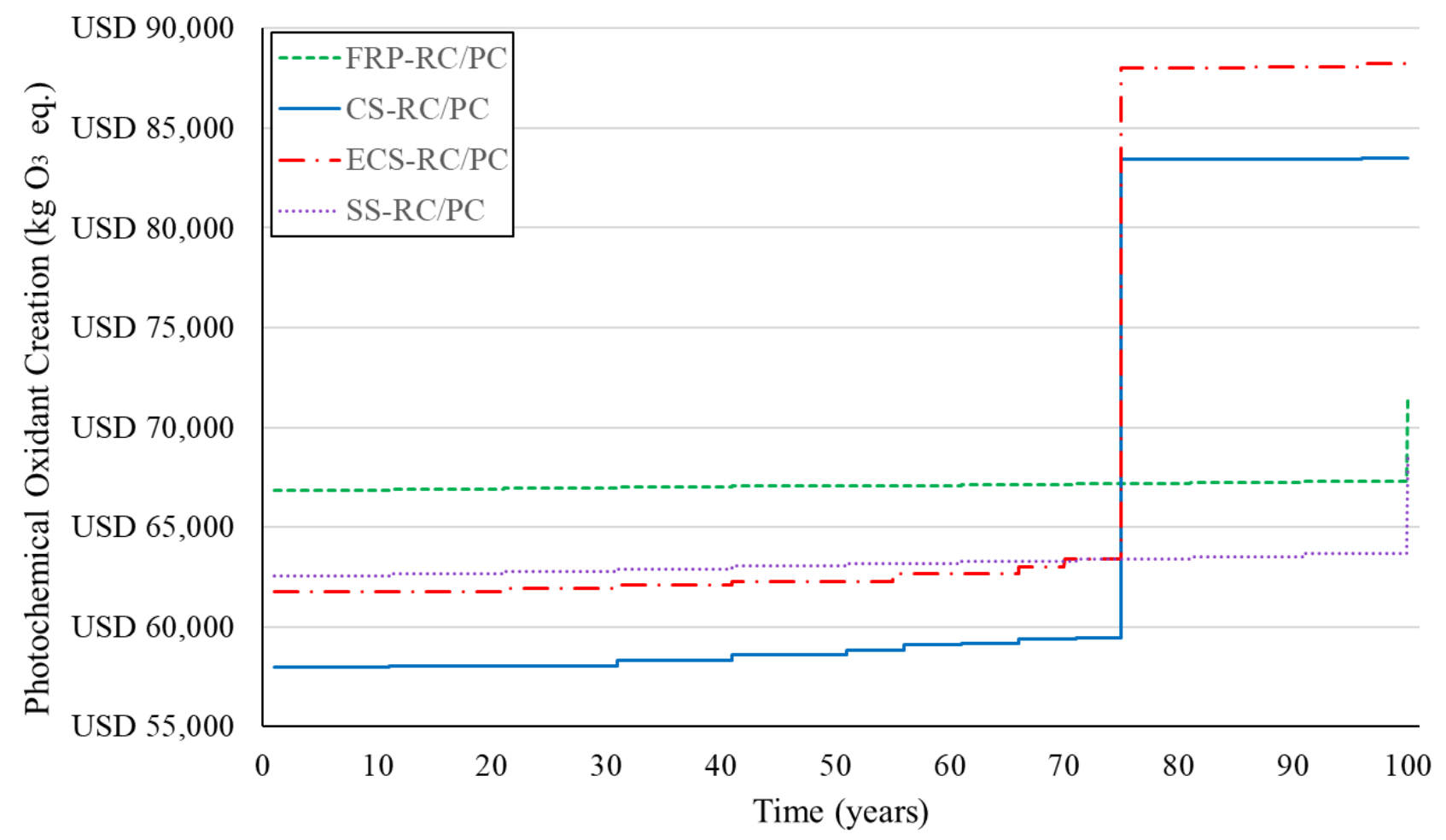

Figure 9-LCIA results: Photochemical Oxidant Creation 


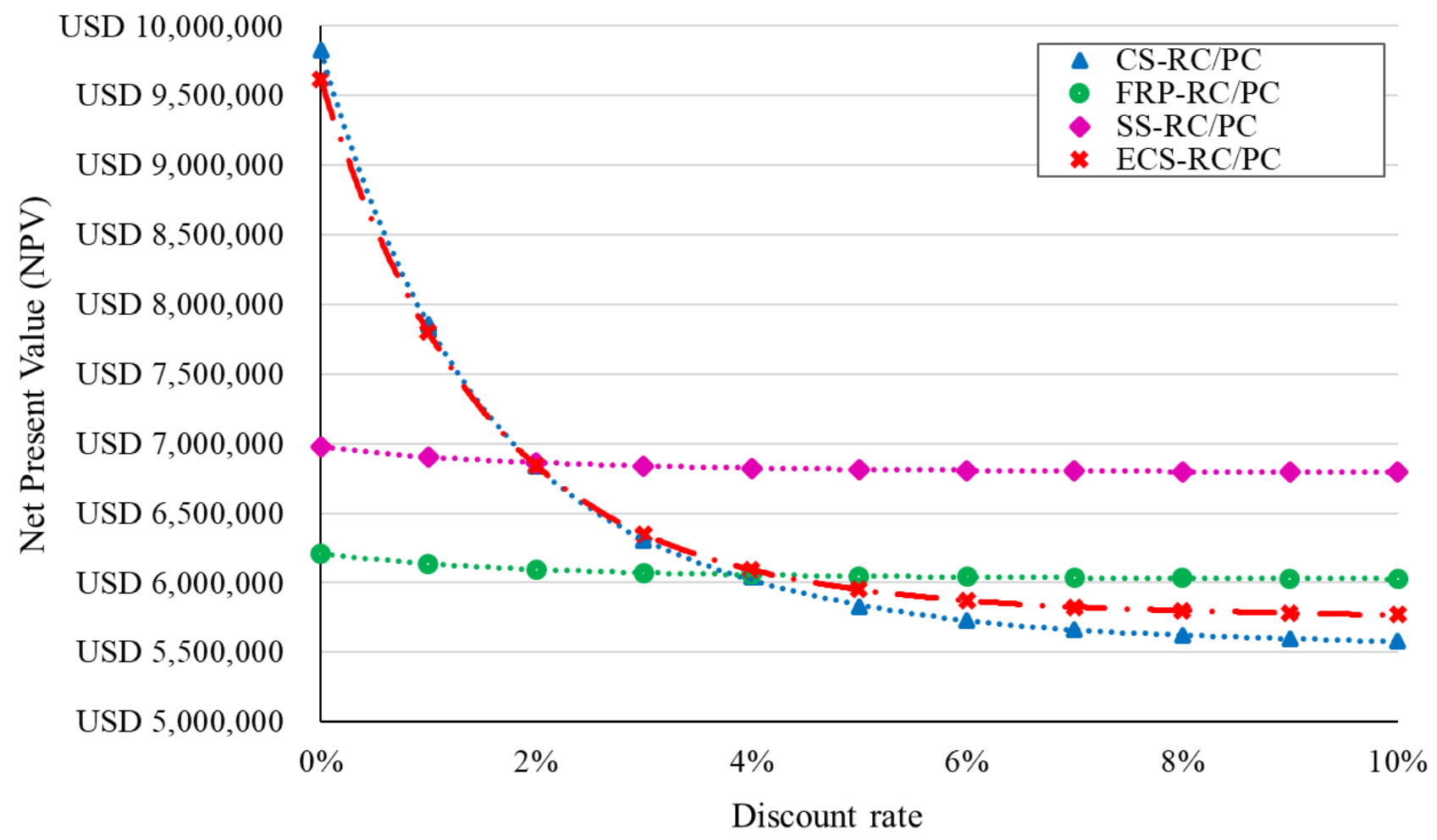

Figure 10 - Sensitivity analysis of LCC results to the discount rate 


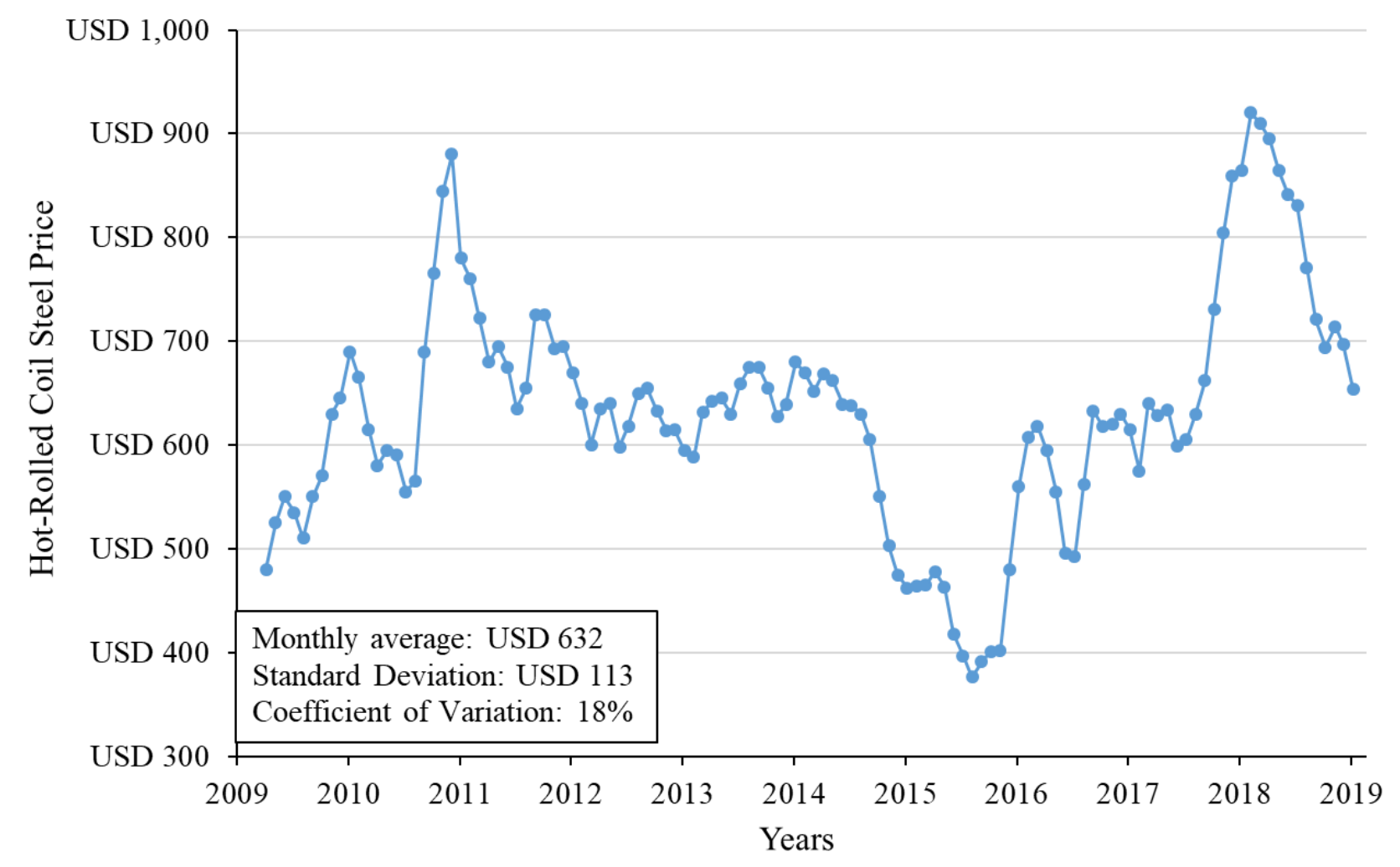

Figure 11 - US Midwest Domestic Hot-Rolled Coil Steel Monthly Price (2009-2019) 


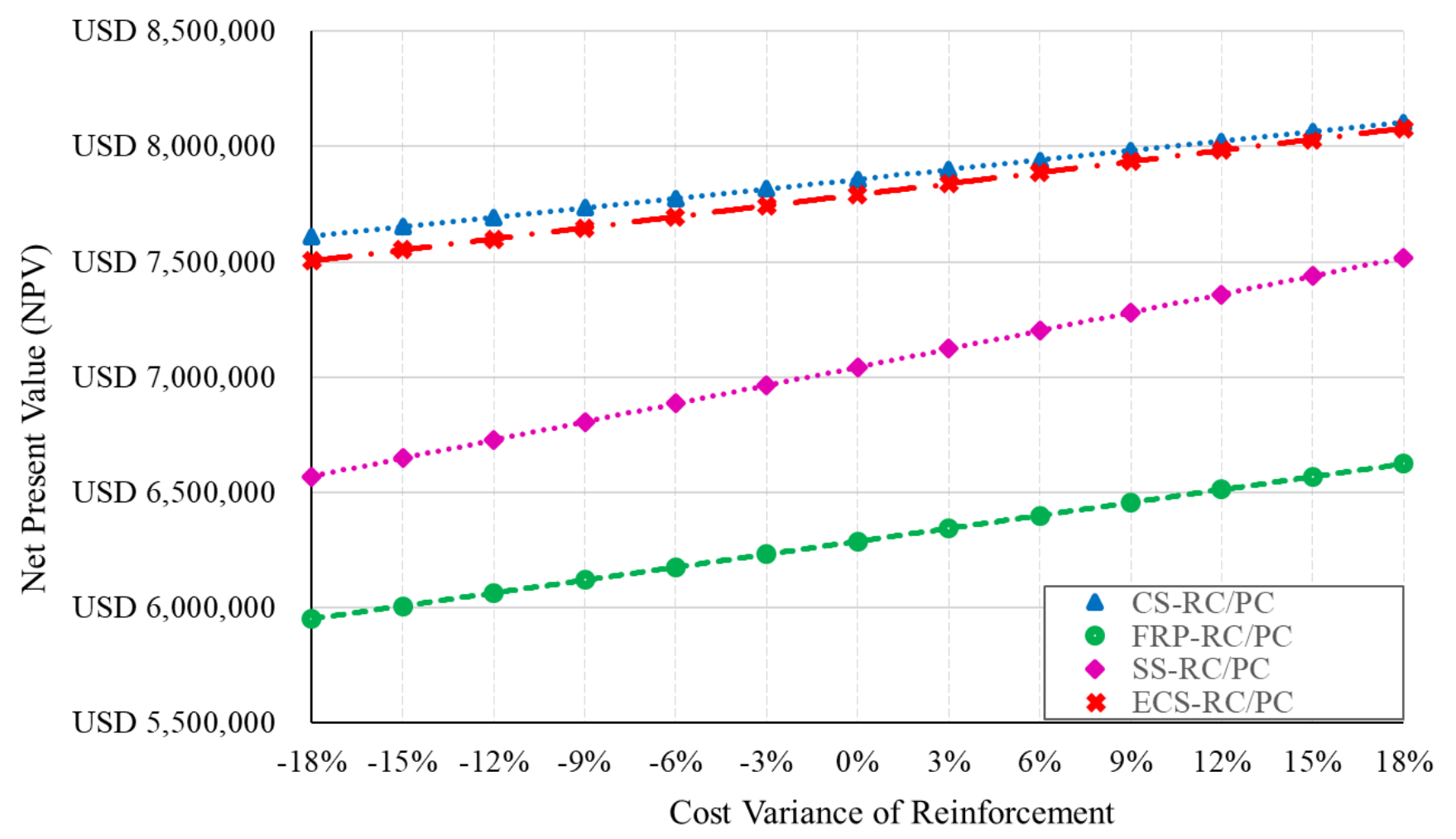

Figure 12 - Sensitivity analysis of LCC results to the Cost of Reinforcement 


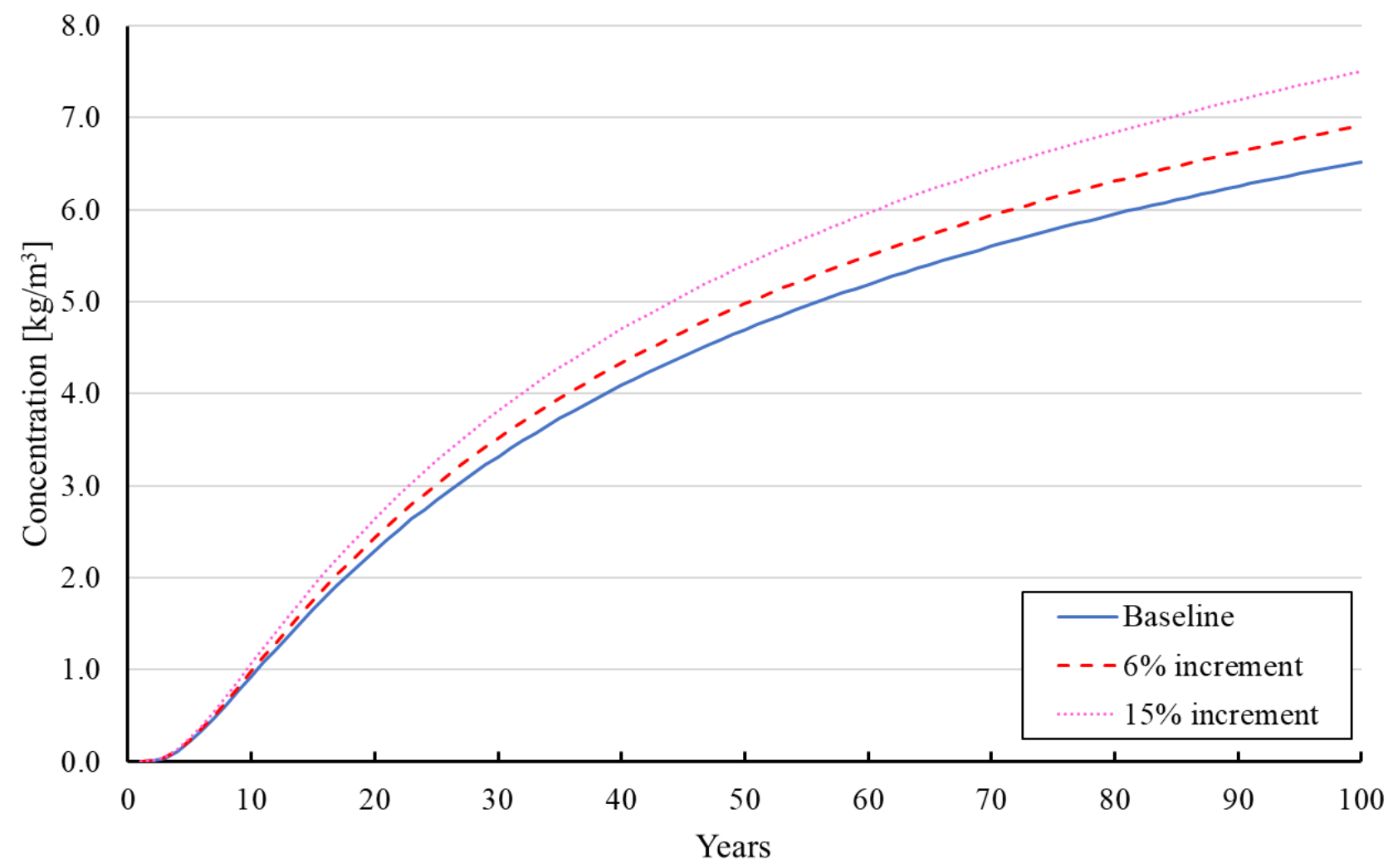

Figure 13 - Variation of Chloride Concentration over time at depth $76.2 \mathrm{~mm}$ for CSRC/PC and ECS-RC/PC 


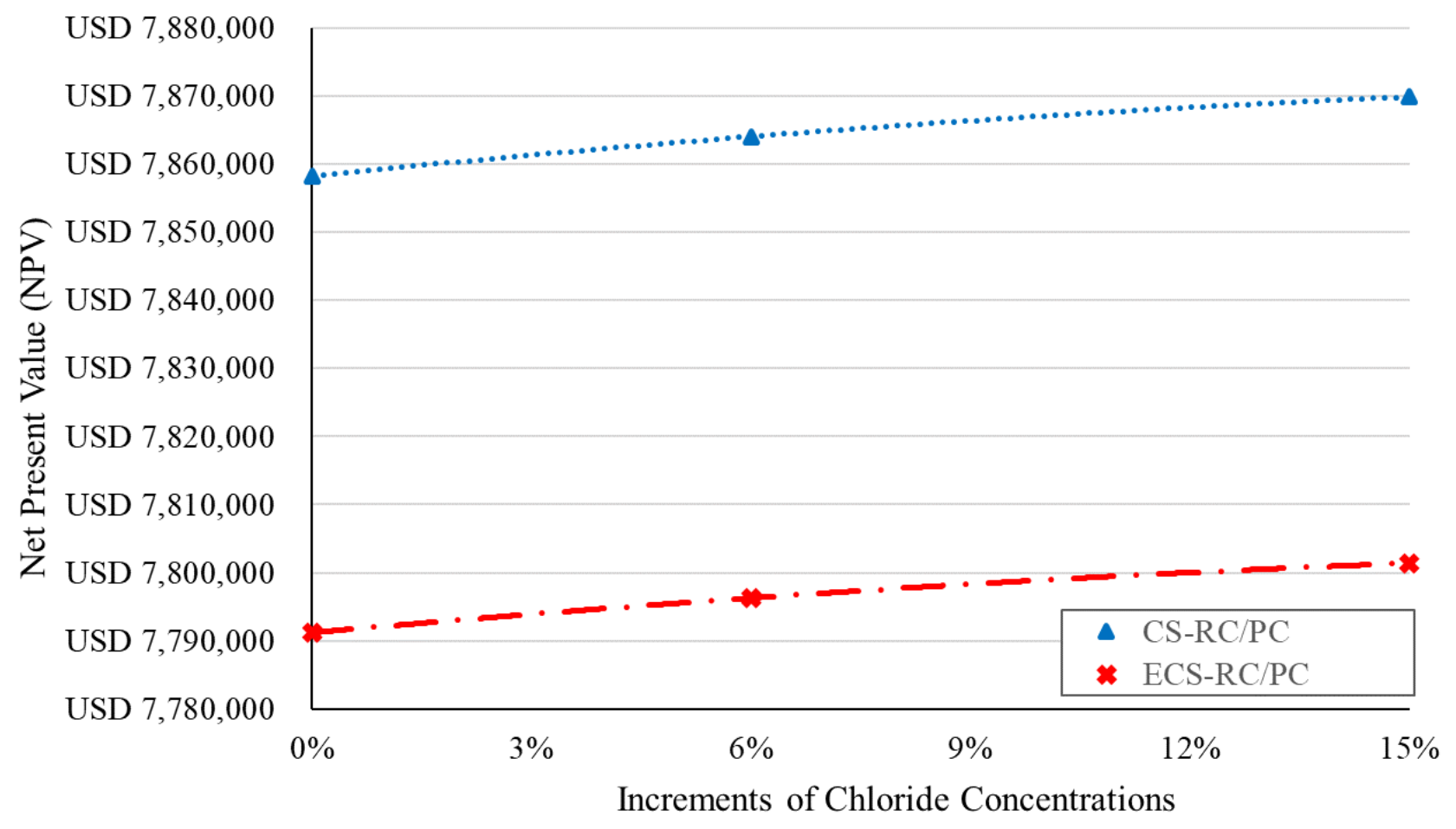

Figure 14 - Sensitivity analysis of LCC results to the Variation of Chloride Concentration 